\title{
Perspective \\ Priority Activities in Child and Adolescent Tuberculosis to Close the Policy-Practice Gap in Low- and Middle-Income Countries
}

\author{
Karen du Preez ${ }^{1, *}$, Betina Mendez Alcântara Gabardo ${ }^{2,3}$, Sushil K. Kabra ${ }^{4}{ }^{\complement}$, Rina Triasih ${ }^{5}$, Trisasi Lestari ${ }^{5,6} \mathbb{C}^{\circ}$, \\ Margaret Kal ${ }^{7}$, Bazarragchaa Tsogt ${ }^{8}$, Gantsetseg Dorj ${ }^{9}$, Enkhtsetseg Purev ${ }^{10}$, Thu Anh Nguyen ${ }^{11}$, \\ Lenny Naidoo ${ }^{12}$, Lindiwe Mvusi ${ }^{13}$, Hendrik Simon Schaaf ${ }^{1}$, Anneke C. Hesseling ${ }^{1}$, \\ Andrea Maciel de Oliveira Rossoni ${ }^{2,3}$, Anna Cristina Calçada Carvalho ${ }^{2,3,14}{ }^{\infty}$, \\ Claudete Aparecida Araújo Cardoso 2,3®0, Clemax Couto Sant'Anna 2,3, Danielle Gomes Dell' Orti ${ }^{2}$, \\ Fernanda Dockhorn Costa ${ }^{2}$, Liliana Romero Vega ${ }^{2}$, Maria de Fátima Pombo Sant'Anna ${ }^{2,3}$, Nguyen Binh Hoa ${ }^{15}$, \\ Phan Huu Phuc ${ }^{16}$, Attannon Arnauld Fiogbe 17,18, Dissou Affolabi 18,19 ${ }^{1}$, Gisèle Badoum 17,20,21, \\ Abdoul Risgou Ouédraogo 17,20,21, Tandaogo Saouadogo ${ }^{21}$, Adjima Combary ${ }^{17,22}$, Albert Kuate Kuate ${ }^{17,22}$, \\ Bisso Ngono Annie Prudence ${ }^{22}$, Aboubakar Sidiki Magassouba ${ }^{17,23}$, Adama Marie Bangoura ${ }^{23}$, \\ Alphazazi Soumana ${ }^{17,24}$, Georges Hermana ${ }^{17,25}$, Hervé Gando ${ }^{25}$, Nafissatou Fall ${ }^{17,26}$, Barnabé Gning ${ }^{26}$, \\ Mohammed Fall Dogo ${ }^{17,27}$, Olivia Mbitikon ${ }^{17,25}$, Manon Deffense ${ }^{17}$, Kevin Zimba ${ }^{28}$, Chishala Chabala ${ }^{29,30}$, \\ Moorine Penninah Sekadde ${ }^{31}$, Henry Luzze ${ }^{31}$, Stavia Turyahabwe ${ }^{31}$, John Paul Dongo ${ }^{32}$, Constantino Lopes ${ }^{33}$, \\ Milena dos Santos ${ }^{34}$, Joshua Reginald Francis ${ }^{6}{ }^{(}$, Magnolia Arango-Loboguerrero ${ }^{35}$, Carlos M. Perez-Velez ${ }^{36}$, \\ Kobto Ghislain Koura ${ }^{17,37,38}$ and Stephen M. Graham ${ }^{17,39}$
}

check for

updates

Citation: du Preez, K.; Gabardo,

B.M.A.; Kabra, S.K.; Triasih, R.;

Lestari, T.; Kal, M.; Tsogt, B.; Dorj, G.;

Purev, E.; Nguyen, T.A.; et al. Priority

Activities in Child and Adolescent

Tuberculosis to Close the

Policy-Practice Gap in Low- and

Middle-Income Countries. Pathogens 2022, 11, 196. https://doi.org/ $10.3390 /$ pathogens 11020196

Academic Editor: António Gil Castro

Received: 23 December 2021

Accepted: 29 January 2022

Published: 1 February 2022

Publisher's Note: MDPI stays neutral with regard to jurisdictional claims in published maps and institutional affiliations.

Copyright: (c) 2022 by the authors. Licensee MDPI, Basel, Switzerland. This article is an open access article distributed under the terms and conditions of the Creative Commons Attribution (CC BY) license (https:// creativecommons.org/licenses/by/ $4.0 /)$.
1 Desmond Tutu Tuberculosis Center, Department of Paediatrics and Child Health, Stellenbosch University, Cape Town 8000, South Africa; hss@sun.ac.za (H.S.S.); annekeh@sun.ac.za (A.C.H.)

2 Pediatric Tuberculosis Working Group, Ministry of Health, Brasilia 70304-008, Brazil; betinamalcantara@gmail.com (B.M.A.G.); dearossoni@gmail.com (A.M.d.O.R.); anna.carvalho@ioc.fiocruz.br (A.C.C.C.); claudetecardoso@id.uff.br (C.A.A.C.); clemax01@gmail.com (C.C.S.); danielle.dellorti@saude.gov.br (D.G.D.O.); fernanda.dockhorn@saude.gov.br (F.D.C.); iliana.romero@saude.gov.br (L.R.V.); fatimapombo09@gmail.com (M.d.F.P.S.)

3 Brazilian Network of Tuberculosis Research, REDE TB-Rede Brasileira de Pesquisas em Tuberculose, Rio de Janeiro 21941-909, Brazil

4 Department of Pediatrics, All India Institute of Medical Sciences, New Delhi 110029, India; skkabra@hotmail.com

5 Faculty of Medicine, Public Health and Nursing, Universitas Gadjah Mada, Yogyakarta 55281, Indonesia; rina_triasih@yahoo.com (R.T.); trisasilestari@gmail.com (T.L.)

6 Menzies School of Health Research, Charles Darwin University, Darwin, NT 0810, Australia; josh.francis@menzies.edu.au

7 National Department of Health, Port Moresby 131, Papua New Guinea; margaretkal1978@gmail.com

8 Mongolian Coalition Against Tuberculosis, Ulaanbaatar 210648, Mongolia; bazra.ts@outlook.com

9 Tuberculosis Surveillance and Research Department, National Center for Communicable Diseases, Ulaanbaatar 210648, Mongolia; dorjgantsetseg1127@gmail.com

10 Tuberculosis Clinic, National Center for Communicable Diseases, Ulaanbaatar 210648, Mongolia; enhuush0425@gmail.com

11 Woolcock Institute of Medical Research, Ha Noi 100000, Vietnam; thuanh.nguyen@sydney.edu.au

12 Health Department, Cape Town 8000, South Africa; Gengiah.Naidoo@capetown.gov.za

13 National TB Control \& Management Cluster, National Department of Health, Pretoria 0187, South Africa; lindiwe.mvusi@health.gov.za

14 Laboratory of Innovations in Therapies, Education and Bioproducts, Oswaldo Cruz Institute, Oswaldo Cruz Foundation, Rio de Janeiro 21045-900, Brazil

15 National Tuberculosis Program, Ha Noi 100000, Vietnam; nguyenbinhhoatb@yahoo.com

16 National Pediatric Hospital, Ha Noi 100000, Vietnam; phuc.h.phan@nhp.org.vn

17 International Union Against Tuberculosis and Lung Disease, 75001 Paris, France; arnauld.fiogbe.consultant@theunion.org (A.A.F.); gisele.badoum.consultant@theunion.org (G.B.); aouedraogo.consultant@theunion.org (A.R.O.); adjicomb@yahoo.fr (A.C.); albert.kuatekuate.consultant@theunion.org (A.K.K.); aboubacar.magassouba.consultant@theunion.org (A.S.M.); alphazazi.soumana.consultant@theunion.org (A.S.); georges.hermana.consultant@theunion.org (G.H.); nafissatou.fall.consultant@theunion.org (N.F.); fall.dogo.consultant@theunion.org (M.F.D.); olivia.mbtikon.consultant@theunion.org (O.M.); deffenseman@gmail.com (M.D.); kgkoura@theunion.org (K.G.K.); steve.graham@rch.org.au (S.M.G.) 
18 National Tuberculosis Program, Cotonou 03 BP 2819, Benin; affolabi_dissou@yahoo.fr

9 Faculty of Health Sciences, University of Abomey-Calavi, Cotonou 03 BP 2819, Benin

20 Health Sciences Unit, University Joseph Ki-Zerbo, Ouagadougou 03 BP 7047, Burkina Faso

21 Ministry of Health National Tuberculosis Program, Ouagadougou 03 BP 7047, Burkina Faso; tandaogo@yahoo.fr

22 National Tuberculosis Program, Yaoundé BP 6000, Cameroon; anniebisso@pnlt.cm

23 National Tuberculosis Program, Conakry 63570, Guinea; adabangou@yahoo.fr

24 National Tuberculosis Program, Niamey 22 646, Niger

25 National Tuberculosis Program, Bangui BP 729, Central African Republic; gahe_gi@yahoo.fr

26 National Tuberculosis Program, Dakar 12000, Senegal; docteurbg2000@yahoo.fr

7 National Tuberculosis Program, Lomé BP 526, Togo

28 Lusaka Provincial Health Office, Ministry of Health, Lusaka 10101, Zambia; drkevinmzimba@gmail.com

29 Department of Pediatrics and Child Health, School of Medicine, University of Zambia, Lusaka 10101, Zambia; cchabala@gmail.com

30 Children's Hospital, University Teaching Hospitals, Lusaka 10101, Zambia

31 National Tuberculosis and Leprosy Program, Kampala 7025, Uganda; moorine.sekadde@gmail.com (M.P.S.); luzzehenry@gmail.com (H.L.); turyahabwestavia@gmail.com (S.T.)

32 The Union Uganda Office, Kampala 7025, Uganda; jpdongo@theunion.org

33 National Tuberculosis Program, Ministerio da Saude, Dili NM 87109, Timor-Leste; costa_tb@yahoo.com

34 Hospital Nacional Guido Valadares, Ministerio da Saude, Dili NM 87109, Timor-Leste; milenalaysantos@yahoo.com

35 Colombian Association of Pediatric Pulmonology, National University of Colombia, Bogota 500001, Colombia; MagnoliArango@hotmail.com

36 Division of Infectious Diseases, University of Arizona College of Medicine, Tucson, AZ 85721, USA; cmperezvelez@gmail.com

37 COMUE Sorbonne Paris Cité, Faculté des Sciences Pharmaceutiques et Biologiques, Université Paris Descartes, 75006 Paris, France

38 École Nationale de Formation des Techniciens Supérieurs en Santé Publique et en Surveillance Epidémiologique, Université de Parakou, Parakou 03 BP 351, Benin

39 Department of Pediatrics, Murdoch Childrens Research Institute, University of Melbourne Royal Children's Hospital, Melbourne, VIC 3052, Australia

* Correspondence: karen_dupreez@sun.ac.za; Tel.: +27-21-938-9174

Abstract: Over the past 15 years, and despite many difficulties, significant progress has been made to advance child and adolescent tuberculosis (TB) care. Despite increasing availability of safe and effective treatment and prevention options, TB remains a global health priority as a major cause of child and adolescent morbidity and mortality-over one and a half million children and adolescents develop TB each year. A history of the global public health perspective on child and adolescent TB is followed by 12 narratives detailing challenges and progress in 19 TB endemic low and middle-income countries. Overarching challenges include: under-detection and underreporting of child and adolescent $\mathrm{TB}$; poor implementation and reporting of contact investigation and TB preventive treatment services; the need for health systems strengthening to deliver effective, decentralized services; and lack of integration between TB programs and child health services. The COVID-19 pandemic has had a significant negative impact on case detection and treatment outcomes. Child and adolescent TB working groups can address country-specific challenges to close the policy-practice gaps by developing and supporting decentral ized models of care, strengthening clinical and laboratory diagnosis, including of multidrug-resistant TB, providing recommended options for treatment of disease and infection, and forging strong collaborations across relevant health sectors.

Keywords: tuberculosis; child; adolescent; national tuberculosis program

\section{Introduction}

Over 60 years ago, frustration was first expressed with the persistent neglect of tuberculosis (TB) in children, defined as $<15$ years of age, particularly with the missed opportunity to prevent severe disease and mortality with isoniazid [1]. It was not until 50 years later that 
the Stop TB Strategy was launched in 2006 by the World Health Organization (WHO) and Stop TB Partnership as a new global strategy that focused on the needs of "both adults and children" irrespective of sputum smear status committing to "address TB/HIV, MDR-TB and other challenges", including TB in "prisoners, refugees and other high-risk groups" [2]. In the same year, the WHO Stop TB Partnership Child TB Sub-group of the DOTS Expansion Working Group published the first guidance for National Tuberculosis Programs (NTP) on the management of TB in children [3]. The guidance included a recommendation that all children should be managed as part of routine NTP operations. It is only in the last decade that NTPs in TB endemic countries have begun to provide greater attention to child TB, with some milestones highlighted in the WHO's recent Global TB Report, shown in Figure 1 [4].
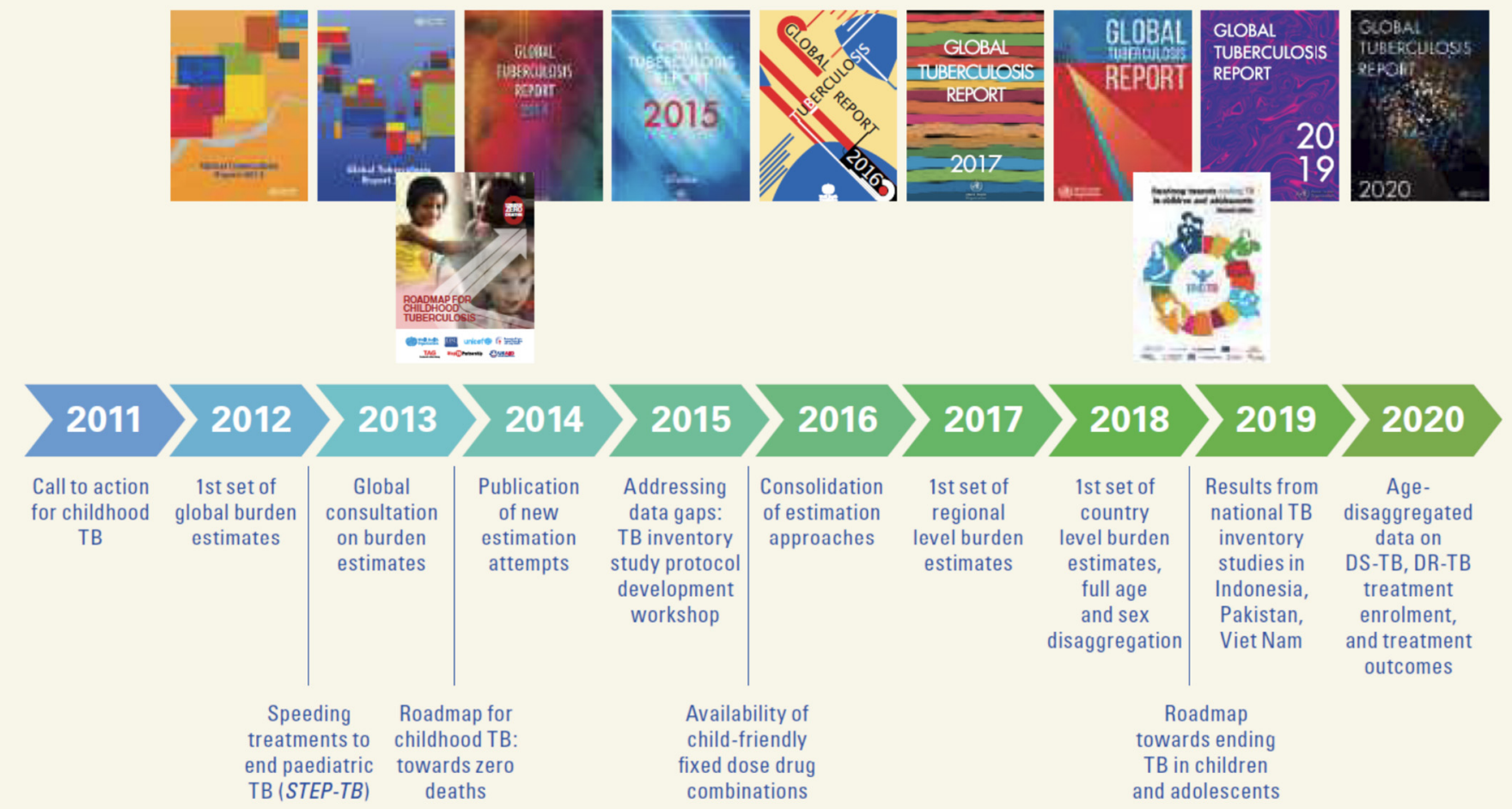

2020

Figure 1. Global milestones related to TB in children and adolescents, 2011-2020. Reprinted from Ref. [4].

A collective "Call to action for childhood TB" followed the first international child TB meeting, held in March 2011, which precipitated efforts to strengthen national surveillance data, as well as advocacy $[5,6]$. The first global estimates for TB in children $(<15$ years) were published in the 2012 WHO Global TB Report, a roadmap for child TB was published by multiple international stakeholders in 2013, and the second edition of the WHO guidance for NTPs was published in 2014 [7,8]. The critical importance of national data for child and adolescent TB was recognized, and, with time, the WHO recommended age-disaggregated reporting of all TB case notifications, including clinically diagnosed pulmonary TB and extrapulmonary TB [4,9]. The WHO's End TB Strategy, that explicitly included children to a greater extent than previous global strategies, was launched in 2015, as were the first child-friendly and appropriately dosed fixed-dose combinations for the treatment of disease and infection in young children $[10,11]$. This led to regional consultations that brought together representatives of NTPs and child health within TB endemic countries, and to a greater recognition than previously of the need for cross-cutting collaboration between TB and child health services with the establishment of child TB working groups by NTPs [12]. At this time, the specific needs of adolescents (10-19 years) with TB began to be recognized, with the first estimates of age-disaggregated data [13]. The Child TB subgroup 
was upgraded to the Child and Adolescent TB Working Group, and the international roadmap was updated to include adolescents in 2018 [14].

$\mathrm{TB}$ in children and adolescents is a global health priority, with more than 1.5 million TB children and adolescents (0-19 years) developing TB each year [4]. Children represent $11 \%$ of the global TB burden but $16 \%$ of deaths, and the majority of the estimated 226,000 TB-related deaths in children each year are either not detected or not reported. The proportion of total TB caseload reported in 2019 that were children is shown by country in Figure 2 [15]. In 2021, the WHO reviewed recent evidence to inform new recommendations [16]. The updated and consolidated WHO guidelines on the management of TB in children and adolescents are now published, complemented by an operational handbook to aid implementation $[17,18]$.

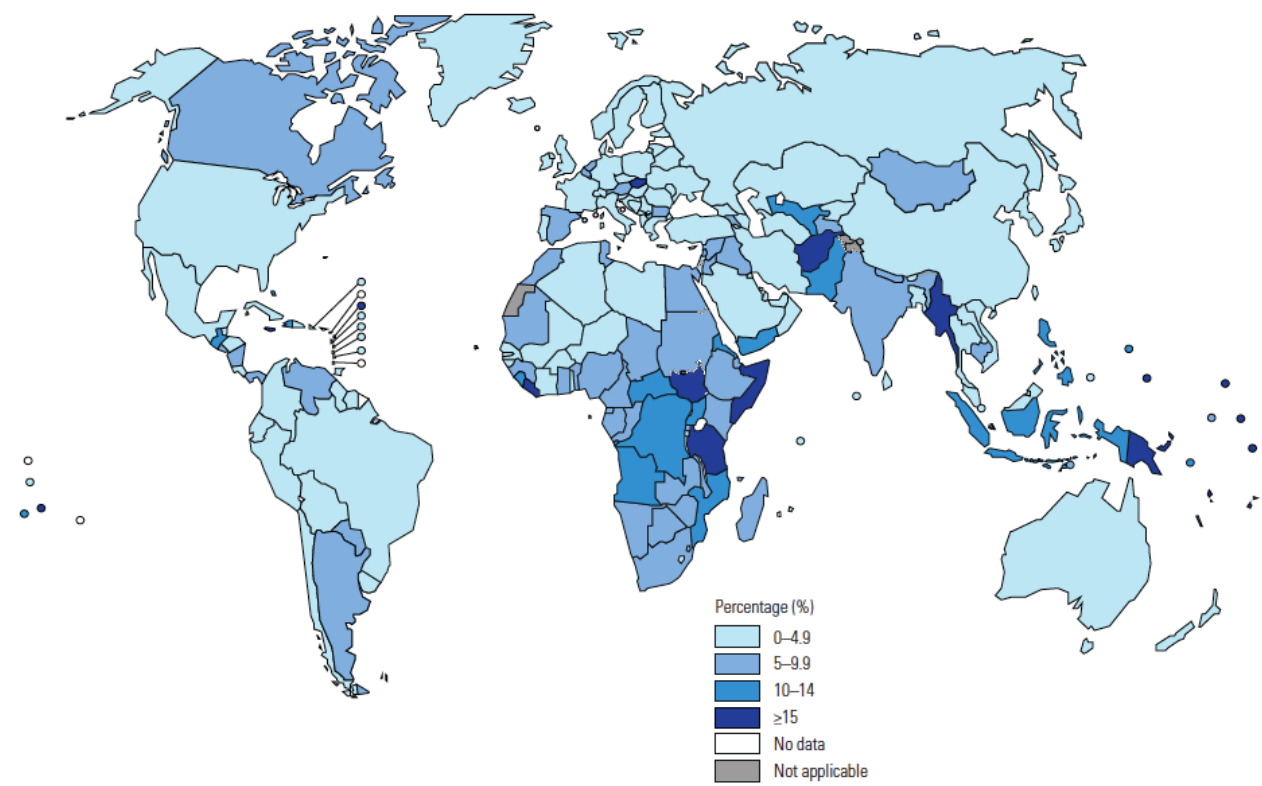

Figure 2. Percentage of new and relapse TB cases that were children (aged <15 years) in 2019. Reprinted from Ref. [4].

This perspective article aims to provide a series of viewpoints that specifically identifies priority actions to address the policy-practice gap in TB endemic countries and global regions. Indicators relevant to detection, treatment, and prevention of TB in children, as reported for the recent WHO Global TB Report by countries [4] represented in this article, are listed in Table 1.

Table 1. Data reported by countries in this review as included in the current $2021 \mathrm{WHO}$ Global TB Report [15].

\begin{tabular}{|c|c|c|c|c|c|c|}
\hline Country & $\begin{array}{c}\text { WHO } \\
\text { High-Burden } \\
\text { Country List } \\
\text { Inclusion }\end{array}$ & $\begin{array}{l}\text { Total TB } \\
\text { Incidence } \\
2020 \text { Data }\end{array}$ & $\begin{array}{c}\text { Treatment } \\
\text { Coverage, } 2020 \\
\% \text { Notified of } \\
\text { Estimated }\end{array}$ & $\begin{array}{l}\text { Proportion of } \\
\text { Notified TB } \\
\text { Cases Are } \\
\text { Children } \\
\text { (<15 years) }\end{array}$ & $\begin{array}{c}\text { Treatment } \\
\text { Success Rate } \\
2019 \text { Cohort }\end{array}$ & $\begin{array}{c}\text { TPT Coverage } \\
\text { for Eligible } \\
\text { Young Child } \\
\text { (<5 Years) TB } \\
\text { Contacts }\end{array}$ \\
\hline Benin & - & 6700 & $58 \%$ & $5 \%$ & $89 \%$ & NR \\
\hline Brazil & TB; TB/HIV & 96,000 & $78 \%$ & $3 \%$ & $69 \%$ & $59 \%$ \\
\hline Burkina Faso & - & 9600 & $59 \%$ & $3 \%$ & $81 \%$ & $24 \%$ \\
\hline Cameroon & TB/HIV & 46,000 & $48 \%$ & $5 \%$ & $86 \%$ & $43 \%$ \\
\hline $\begin{array}{l}\text { Central African } \\
\text { Republic }\end{array}$ & TB; TB/HIV & 26,000 & $48 \%$ & $13 \%$ & $81 \%$ & $16 \%$ \\
\hline Colombia & - & 19,000 & $64 \%$ & $3 \%$ & $75 \%$ & $38 \%$ \\
\hline
\end{tabular}


Table 1. Cont.

\begin{tabular}{|c|c|c|c|c|c|c|}
\hline Country & $\begin{array}{c}\text { WHO } \\
\text { High-Burden } \\
\text { Country List } \\
\text { Inclusion }\end{array}$ & $\begin{array}{l}\text { Total TB } \\
\text { Incidence } \\
2020 \text { Data }\end{array}$ & $\begin{array}{c}\text { Treatment } \\
\text { Coverage, } 2020 \\
\text { \% Notified of } \\
\text { Estimated }\end{array}$ & $\begin{array}{l}\text { Proportion of } \\
\text { Notified TB } \\
\text { Cases Are } \\
\text { Children } \\
\text { (<15 years) }\end{array}$ & $\begin{array}{l}\text { Treatment } \\
\text { Success Rate } \\
2019 \text { Cohort }\end{array}$ & $\begin{array}{l}\text { TPT Coverage } \\
\text { for Eligible } \\
\text { Young Child } \\
\text { (<5 Years) TB } \\
\text { Contacts }\end{array}$ \\
\hline Guinea & TB/HIV & 23,000 & $66 \%$ & $6 \%$ & $89 \%$ & NR \\
\hline India & $\begin{array}{l}\text { TB; TB/HIV; } \\
\text { MDR/RR-TB }\end{array}$ & $2,590,000$ & $63 \%$ & $6 \%$ & $84 \%$ & $42 \%$ \\
\hline Indonesia & $\begin{array}{l}\text { TB; TB/HIV; } \\
\text { MDR/RR-TB }\end{array}$ & 824,000 & $47 \%$ & $9 \%$ & $83 \%$ & $4 \%$ \\
\hline Mongolia & $\begin{array}{c}\text { TB; } \\
\text { MDR/RR-TB }\end{array}$ & 14,000 & $27 \%$ & $12 \%$ & $88 \%$ & $8 \%$ \\
\hline Niger & - & 20,000 & $56 \%$ & $4 \%$ & $83 \%$ & NR \\
\hline $\begin{array}{l}\text { Papua New } \\
\text { Guinea }\end{array}$ & $\begin{array}{l}\text { TB; TB/HIV; } \\
\text { MDR/RR-TB }\end{array}$ & 39,000 & $72 \%$ & $22 \%$ & $73 \%$ & $23 \%$ \\
\hline Senegal & & 20,000 & $65 \%$ & $5 \%$ & $91 \%$ & $33 \%$ \\
\hline South Africa & $\begin{array}{l}\text { TB; TB/HIV; } \\
\text { MDR/RR-TB }\end{array}$ & 328,000 & $58 \%$ & $7 \%$ & $79 \%$ & $51 \%$ \\
\hline Timor Leste & - & 6700 & $48 \%$ & $8 \%$ & $91 \%$ & NR \\
\hline Togo & - & 3000 & $79 \%$ & $3 \%$ & $87 \%$ & NR \\
\hline Uganda & TB; TB/HIV & 90,000 & $68 \%$ & $12 \%$ & $82 \%$ & $34 \%$ \\
\hline Vietnam & $\begin{array}{c}\text { TB; } \\
\text { MDR/RR-TB }\end{array}$ & 172,000 & $58 \%$ & $1 \%$ & $91 \%$ & $5 \%$ \\
\hline Zambia & $\begin{array}{l}\text { TB; TB/HIV, } \\
\text { MDR/RR-TB }\end{array}$ & 59,000 & $68 \%$ & $6 \%$ & $89 \%$ & $28 \%$ \\
\hline
\end{tabular}

\section{Overview of National Perspectives}

A range of national and regional perspectives from TB endemic settings are presented by health workers and national leaders involved in providing TB care for children and adolescents. Table 2 provides a summary of current national programmatic initiatives or activities that are specific for child and adolescent TB. Efforts to address the policy-practice gap at the national level have increased and are variable between countries. Until recently, many NTPs had very limited policy guidelines relating to children, and they did not have national child TB Working Groups. Attention to the needs of adolescents is even more recent, if at all occurring previously [19]. Diagnostic approaches follow similar principles [8], but adaptation and implementation vary by setting and facility level. Countries, such as Papua New Guinea and Brazil, utilize home-grown scoring systems. However, the various approaches often include investigations, such as the tuberculin skin test, that are no longer widely available.

Most countries now procure the dispersible, fixed-dose formulations of first-line drugs [11]. While progress is being made in the development of more child-friendly, appropriately dosed second-line drugs, the treatment of multidrug-resistant (MDR) TB remains challenging. The recent update by the WHO to support the use of the new drugs, bedaquiline and delamanid, for all ages is a major step forward toward all-oral regimens for children, thereby negating the need for injectables [16,17]. Increasing the coverage of household contact management with integrated, decentralized models of care is now a major focus, greatly enabled by having a range of safer and shorter regimens recommended for TB preventive treatment (TPT) [20]. However, the programmatic systems to record and report the main indicators of household screening coverage, along with the initiation and completion of TPT in eligible contacts, are still being established. Greater age-disaggregation of programmatic data through the child and adolescent age groups is hugely important given the major variations in epidemiological risks, diagnostic patterns, and treatment outcomes from birth until early adulthood. This is now requested for the 
WHO report and facilitated by the increasing use of electronic, rather than paper-based, surveillance systems.

Table 2. A summary of support for "child-friendly" tuberculosis management by region and country.

\begin{tabular}{|c|c|c|c|c|c|c|c|c|c|}
\hline Country & $\begin{array}{c}\text { Child TB } \\
\text { Working } \\
\text { Group }\end{array}$ & $\begin{array}{c}\text { Specific } \\
\text { NTP } \\
\text { Guidelines * }\end{array}$ & $\begin{array}{c}\text { Specific } \\
\text { Inclusion of } \\
\text { Adolescents }\end{array}$ & $\begin{array}{l}\text { Diagnostic } \\
\text { Approach or } \\
\text { Algorithm }\end{array}$ & $\begin{array}{l}\text { Child- } \\
\text { Friendly } \\
\text { Treatment } \\
\text { Options }\end{array}$ & $\begin{array}{c}\text { TPT } \\
\text { Options ** }\end{array}$ & $\begin{array}{l}\text { Programmatic } \\
\text { Indicators for } \\
\text { Contact } \\
\text { Management }\end{array}$ & $\begin{array}{l}\text { Training } \\
\text { Manual and } \\
\text { Job Aides }\end{array}$ & $\underset{\substack{\text { Age- } \\
\text { Disaggregated } \\
\text { Data \# }}}{ }$ \\
\hline \multicolumn{10}{|c|}{ America Region } \\
\hline Brazil & Yes & Yes & Partial & Yes & Yes & $6 \mathrm{H}, 3 \mathrm{HP}, 4 \mathrm{R}$ & Yes & Yes & Yes \\
\hline Colombia & No & No & No & Yes & Yes & $\begin{array}{c}\text { 6H, } \\
\text { 3HP (HIV+) }\end{array}$ & Yes & No & Partial \\
\hline \multicolumn{10}{|l|}{ Africa Region } \\
\hline Benin & Yes & Yes & No & Yes & Partial & $6 \mathrm{H}$ & Yes & No & No \\
\hline $\begin{array}{l}\text { Burkina } \\
\text { Faso }\end{array}$ & No & Yes & No & Yes & Yes & $\begin{array}{l}\text { 3RH (HIV-) } \\
6 \mathrm{H}(\mathrm{HIV}+)\end{array}$ & Yes & Yes & No \\
\hline Cameroon & Partial & Yes & Yes & Yes & Yes & $6 \mathrm{H}$ & Yes & Yes & Yes \\
\hline $\begin{array}{l}\text { Central } \\
\text { African } \\
\text { Republic }\end{array}$ & No & Yes & No & Yes & Yes & $6 \mathrm{H}, 3 \mathrm{RH}$ & No & No & Yes \\
\hline Guinea & Partial & Yes & Yes & Yes & Yes & $6 \mathrm{H}$ & Yes & Yes & Yes \\
\hline Niger & No & Yes & Yes & Yes & Yes & $6 \mathrm{H}$ & Yes & Yes & Yes \\
\hline Senegal & Yes & Yes & No & Yes & Yes & $6 \mathrm{H}$ & Yes & Yes & Yes \\
\hline South Africa & No & Yes & No & Yes & Partial & $\begin{array}{c}6 \mathrm{H} \\
(3 \mathrm{RH}, 3 \mathrm{HP})^{¥}\end{array}$ & Yes & No & Yes \\
\hline Togo & No & No & No & No & Yes & $6 \mathrm{H}, 3 \mathrm{RH}$ & No & No & No \\
\hline Uganda & Yes & Yes & Partial & Yes & Yes & $\begin{array}{l}\text { 3Rम, } 6 \text { H, } \\
\text { 3HP }\end{array}$ & Yes & Yes & Yes \\
\hline Zambia & Yes & Yes & Partial & Yes & Yes & $\begin{array}{c}6 \mathrm{H}, 3 \mathrm{RH}, \\
3 \mathrm{HP}\end{array}$ & Yes & Yes & Yes \\
\hline \multicolumn{10}{|c|}{ South-East Asia Region } \\
\hline India & Yes & Yes & Yes & Yes & Yes & $6 \mathrm{H}, 3 \mathrm{HP}$ & Yes & Yes & Yes \\
\hline Indonesia & No & Yes & No & Yes & Yes & $\begin{array}{c}\text { 6म,3Rम, } \\
\text { 3HP }\end{array}$ & Yes & No & Yes \\
\hline Timor Leste & No & Yes & No & Yes & Yes & $6 \mathrm{H}, 3 \mathrm{RH}$ & Yes & No & Yes \\
\hline \multicolumn{10}{|c|}{ Western Pacific Region } \\
\hline Mongolia & Partial & Yes & No & Yes & Yes & $\begin{array}{c}6-9 \mathrm{H}, 3 \mathrm{HP}, \\
1 \mathrm{HP}\end{array}$ & Yes & No & No \\
\hline $\begin{array}{l}\text { Papua New } \\
\text { Guinea }\end{array}$ & No & Yes & No & Yes & Partial & $\begin{array}{c}6 \mathrm{H}, 3 \mathrm{RH}, \\
3 \mathrm{HP}\end{array}$ & Partial & No & Yes \\
\hline Vietnam & Yes & Yes & No & Yes & Yes & $\begin{array}{c}6 \mathrm{H}, 3 \mathrm{RH}, 4 \mathrm{R}, \\
3 \mathrm{HP}\end{array}$ & Yes & Yes & Yes \\
\hline \multicolumn{10}{|c|}{$\begin{array}{l}\text { * Guidelines as stand-alone manual or chapter within National TB Program (NTP) guidelines; }{ }^{* *} \text { These TB } \\
\text { preventive treatment (TPT) options are for contacts of drug-susceptible TB cases, N.B. some NTPs, such as } \\
\text { Mongolia and Indonesia, also have TPT guidelines that include levofloxacin for contacts of multidrug-resistant TB } \\
\text { cases; \# Able to report notifications and treatment outcomes by age groups of } 0-4 \text { years, } 5-9 \text { years, } 10-14 \text { years, } \\
\text { and } 15-19 \text { years; }{ }^{\wedge} \text { Programmatic indicators of coverage, TPT uptake and TPT completion. } ¥ 3 \mathrm{RH} \text { and } 3 \mathrm{HP} \text { are } \\
\text { included as planned TPT options for children in South Africa. } 6 \mathrm{H}=6 \text { months isoniazid; } 3 \mathrm{HP}=3 \text { months isoniazid } \\
\text { and rifapentine; } 4 \mathrm{R}=4 \text { months rifampicin; } 3 \mathrm{RH}=3 \text { months rifampicin and isoniazid. Green: fully implemented; } \\
\text { Orange: partially implemented; Red (pink): not implemented. }\end{array}$} \\
\hline
\end{tabular}

\subsection{Brazil: Progress and Challenges in the Control of TB in Childhood and Adolescence}

Brazil is currently listed by the WHO as a high-burden country for TB and TB/HIV, despite the implementation of TB control activities for over 50 years. Intradermal BCG vaccination of infants and young children up to five years old was introduced in the 1970s, as was "short-course" treatment for new cases. The dispensing of medications exclusively in public health services with obligatory notification allowed standardization of treatment, aggregation of data by the Ministry of Health and limited the risk of emergence of drugresistant TB. In the 1980s, the Unified Health System, or Sistema Único de Saúde (SUS), was implemented to guarantee free healthcare, and, with the advent of the HIV epidemic, this included preventive measures and the distribution of antiretroviral (ARV) drugs. For the last 20 years, TB case notification has been completed through the Notifiable Diseases Information System, or Sistema de Informação de Agravos de Notificação (SINAN), which has strengthened surveillance and provided epidemiological data for monitoring and evaluation. National programmatic recommendations for TB are periodically updated and the NTP manual has included chapters that relate to children and adolescents since 2002.

Children (0-9 years) and adolescents (10-19 years) accounted for $1.7 \%$ and $6.4 \%$, respectively, of the total 68,706 TB cases reported in Brazil in 2020 [21]. The proportions are lower than expected, especially in children, suggesting under-detection and/or under- 
reporting. Xpert MTB/RIF was introduced in 2013 and Xpert MTB/RIF Ultra in 2019. There is likely to be under-detection with bacteriological and clinical diagnosis in adolescents, as well, as suggested by a recent retrospective study of a vulnerable population with poor living conditions in Rio de Janeiro [22]. Since 2011, WHO-recommended treatment regimens for adolescents and children have been applied, and child-friendly dispersible combined formulations are now available. Treatment outcomes for the 2019 cohorts of child and adolescent cases were: treatment success rates of $71 \%$ and $75 \%$; deaths $3.8 \%$ and $1.5 \%$; and lost to follow-up were $8.7 \%$ and $12.5 \%$, respectively [21]. Risk factors for unfavorable outcomes in adolescents have been identified, such as extreme vulnerability and HIV infection [23]. Brazil is not a high-burden country for MDR TB, but this is also under-detected. From 2016 to 2020, only $0.2 \%$ of MDR-TB cases occurred in children (0-9 years), and $5.4 \%$ in adolescents (10-19 years) [21]. The new second-line oral drugs of bedaquiline and delamanid are available.

The WHO has recently set targets for implementation of TPT, primarily among young child contacts and people living with HIV [4,15]. In 2018, an information system for TB infection (TBI) notification and TPT was implemented with adoption by all federated units in 2021. The COVID-19 pandemic compromised contact screening coverage, which fell from $63 \%$ in 2019 to $55 \%$ in 2020 [21]. However, TBI notifications increased during this period, with children and adolescents accounting for $25.5 \%$ of cases receiving TPT. Children and adolescents in Brazil participated in landmark international trials that provided evidence of effectiveness and safety of shorter TPT options now recommended by the WHO $[24,25]$. These TPT options of $4 \mathrm{R}$ (daily rifampicin for 4 months) and 3HP (once weekly rifapentine and isoniazid for 3 months) are now available in Brazil, as is the interferon-gamma release assay to test for infection.

The Ministry of Health created a "child TB working group" in 2017. This is comprised of specialists in child and adolescent TB, and a major task was to develop strategies that would enable the decentralization of diagnosis and treatment to the level of the Primary Health Care (PHC) Units. This strategy utilizes a child TB clinical diagnostic scoring system developed by the Ministry of Health, in 2002, and has since been validated [26]. The health worker is provided with guidance on further investigation and decisions to treat for $\mathrm{TB}$ at a decentralized level of care [27].

Despite the aforementioned efforts and leadership within the Ministry of Health, TB is still neglected in children and adolescents in Brazil. One major challenge is that the health system for children and adolescents is not well adapted to provide TB care. There is a low implementation of policy guidelines, as well as available tools for detection and prevention. It is necessary to give more attention and voice to children and adolescents, and to listen to them, providing a model of care where they feel welcomed and that takes into account epidemiological, anthropological, social, and economic aspects $[28,29]$. Only then will it be possible to replace the suffering imposed by TB with a future that seeks to eliminate this disease.

\subsection{India: Child and Adolescent TB Challenges and Way Forward}

The India TB report estimated that 342,000 children in India developed TB in 2019, accounting for $31 \%$ of the global burden of child TB, and $13 \%$ of the national TB burden [30]. To improve the care and prevention of TB in children and adolescents, major changes have recently been made by the National TB Elimination Program (NTEP) of government that include: improved diagnostic algorithm facilitating use of rapid molecular tests and detection of drug-resistant TB in children, introduction of child-friendly drug regimens, pediatric-oriented monitoring, and updated options for TB preventive treatment [31].

Diagnosis is a major challenge. To improve case detection and treatment, the NTEP has introduced a new diagnostic algorithm so that chest X-ray (CXR) is an initial, routine investigation in children with or without history of TB contact who have TB-related symptoms, such as persistent unremitting cough, weight loss, or failure to gain weight. Clinical diagnosis is still important due to the paucibacillary nature of disease in children. To improve yield of bacteriologically confirmed TB in children, the NTEP now recommends 
use of molecular tests (such as Xpert MTB/RIF or Truenat TB test) in preference to smear examination in pulmonary, as well as extrapulmonary TB [27]. The sensitivity of molecular diagnostics varies from $15 \%$ to $30 \%$ in tertiary research settings, to less than $10 \%$ under programmatic conditions [32,33]. Of a total of 94,415 presumptive TB cases in Indian children presenting to public and private clinics in ten cities in India in which free-of-charge upfront Xpert MTB/RIF was used, Xpert was positive in 6.6\% compared to $2 \%$ on smear microscopy for acid-fast bacilli (AFB) [33]. Around half of the specimens tested were non-sputum, and nearly $90 \%$ of positive cases commenced treatment on the day of diagnosis. Such an approach is associated with a considerable increase in health system costs.

All children diagnosed with TB are registered on an electronic portal called "NIKSHYA" that helps with tracking all children to reduce treatment interruptions [31]. There have been major changes to the recommended treatment regimens for children. There is now a single regimen for all types of newly diagnosed TB: rifampicin, isoniazid, pyrazinamide, and ethambutol, during intensive phase, with three drugs (rifampicin, isoniazid, and ethambutol) recommended in the continuation phase due to a high background prevalence of isoniazid resistance. To improve treatment completion rates, a pill box for each child containing a full course of treatment is kept at TB treatment centers from treatment initiation. To identify drug-resistant TB in children, an integrated diagnostic algorithm has also been developed [34]. In the study of upfront Xpert MTB/RIF use, 545 (8.7\%) of 6270 cases with Mycobacterium tuberculosis (M.tb.) complex detected by Xpert were rifampicin-resistant [33]. All diagnostic services are provided free through the NTEP laboratory network [30].

To improve acceptability of national guidelines, it has been important to engage all stakeholders who manage child TB in development of new guidelines and ensure that resources are available to them for treatment of children with TB. This process involved experts and academics and included members of the Indian Academy of Pediatrics. This is a nationally representative organization that signed a memorandum of understanding with the Central TB Division in October 2019 to build public and private sector capacity, which included district level training to strengthen management and notification of child TB cases [30].

TPT is an important NTEP priority, and guidelines for implementation were recently published [30,35]. TPT is now offered to children of all ages who are household contacts of bacteriologically confirmed pulmonary TB patients. Widespread implementation of this activity is being done with support from the general health system. However, there is much to be done to increase coverage. India reported that only $42 \%$ of young children (<5 years) who were household contacts of TB source cases received TPT in 2019 [15]. For child TB index cases, reverse contact tracing to identify the source of infection is also recommended [35].

In summary, there is now strong political will to support implementation of updated NTEP policy guidelines and reach national targets. The major challenges include decentralization of services for detection and prevention, improving case finding utilizing the resources available through the NTEP, and scaling up contact screening and TPT.

\subsection{South Africa: Key Programmatic Opportunities and Challenges to Improving TB Services for Children and Adolescents}

South Africa is among the countries with the highest burden of TB globally, with an estimated total TB incidence of 328,000 (95\% CI 230,000-444,000) in 2020 (Table 1) [15]. The incidence among children under 15 years of age is estimated at 30,000 (95\% CI 19,000-41,000). As much as there has been a gradual decline in TB notifications since 2009 [36], the notification gap remains high $(16,442$ in children $<15$ years). TB has been integrated into the Integrated Management of Childhood Illness package of care for young children since 1998. To prioritize and increase the focus on children, a separate Childhood TB guideline was developed in 2013. At a policy level, child and adolescent TB services are well integrated with other health programs and services. However, despite substantial investment, capacity building, and guideline and policy development, implementation remains sub-optimal 
and varies substantially across provinces, resulting in missed opportunities for prevention, detection, and treatment. In 2020, South Africa reached $66 \%$ of the child TB case finding target agreed upon at the United Nations High Level Meeting for TB, and only $35 \%$ of the target for TPT initiation in eligible child contacts below 5 years [37].

Whilst TPT has been implemented for many years in young and HIV-positive children who are contacts of people diagnosed with infectious TB, reporting on TPT implementation only started in 2017. Many missed opportunities for the prevention of childhood TB remain, and more effort is required in screening child contacts and increasing TPT uptake. A recent review estimated that less than a third of eligible child contacts initiated TPT, and less than a third of those who initiated, completed six months of isoniazid [38]. Qualitative research identified challenges at various levels but specifically noted a lack of training for healthcare workers and inadequate systems to monitor TPT delivery [38,39]. TPT completion is not monitored and reported, but plans are currently in place to include these in the National Indicator Data Set in 2022. Given the poor TPT completion rates, the anticipated revision of national TPT guidelines to include shorter regimens, such as 3 months of daily isoniazid and rifampicin (3HR), recommended by the WHO [20], is eagerly anticipated, while access to 3 months of once weekly rifapentine and isoniazid is not yet available. BCG vaccination at birth is national policy, and, though BCG supply has been restored following recent global shortages, challenges remain in uptake and coverage.

Analysis of routine South African surveillance data for drug-susceptible TB from 2004 to 2016 found that TB case notification rates had declined the least in young children ( $<5$ years) living with HIV and in older adolescents (15-19 year of age), irrespective of HIV status [40]. Therefore, TB control efforts should increase attention to these vulnerable sub-groups. Many young children with uncomplicated TB are still diagnosed at hospitallevel, while a diagnosis could feasibly be made at the PHC level [41,42]. Regular training for PHC workers providing child and maternal health and TB services will increase their confidence and competency to diagnose TB in children [43]. TB meningitis continues to be a common and preventable cause of death or major long-term disability in children [44]. Initial symptoms are non-specific, resulting in missed opportunities for earlier diagnosis, especially at the PHC level [45], while substantial opportunities for prevention through BCG vaccination and TPT remain. In rural or remote areas, access to microbiological testing and $X$-ray services remains a challenge, resulting in delayed presentation and diagnosis of TB. Even in urban areas, where these services are more readily accessible, interpretation of CXRs for child TB [46] and limited attempts to obtain samples for microbiological testing at PHC level remain major challenges to TB diagnosis, especially in young children. Bacteriological confirmation is especially important in children at risk of drug-resistant $\mathrm{TB}$ in this setting.

Of 729,463 children and adolescents routinely registered and treated for drug-susceptible TB in South Africa during 2004-2016, treatment success (cured or treatment completed) was reported in only $81 \%$, and $116,808(16 \%)$ were lost to follow-up during treatment [47]. Mortality whilst on treatment declined during this period to $2 \%$ in 2016. However, the highest mortality was observed in children below 2 years of age and among adolescent females [47]. With close observation, individualized care, and global leadership in expertise and experience, children with drug-resistant TB in South Africa have excellent outcomes, with treatment success in over $90 \%$ [48].

Despite the availability, since 2016, of child-friendly fixed-dose combination formulations for first-line treatment in young children, South Africa only introduced these in mid-2021 due to substantial delays in regulatory approvals. While South Africa has made great advances in adopting decentralized models of care for children with drug-resistant $\mathrm{TB}$, child-friendly formulations are not yet available for many second-line drugs. Therefore, treatment remains complicated by a substantial pill burden, especially for those living with HIV. The shorter and injectable-free drug-resistant TB treatment regimens now allow for decentralized home-based care and a family-centered approach to treatment and monitor- 
ing. Bedaquiline and delamanid have been available for children since 2018, although with some age restrictions in younger children.

South Africa has used electronic case-based TB surveillance data since 2004 and, over the past five years, has invested in strengthening health data systems, including those for TB surveillance. However, more comprehensive indicators and integration of multiple data sources are needed for adequate monitoring and evaluation of child and adolescent TB care. Surveillance should include age-disaggregated data on prevention, TB disease spectrum, and post-TB morbidity and should be available to inform improvement of services at facility level. Strengthened information systems between hospitals and PHC facilities to improve linkage to care for children and adolescents can further improve outcomes [49-53]. With the TB surveillance system as it is now, it is impossible to effectively monitor program performance due to lack of access to the system at district, province, and national levels, where data management and the use of data for action is compromised. A system for program monitoring, interoperable with the NHLS Laboratory information system and death notification system, is urgently required in South Africa.

The impact of COVID-19-related restrictions on TB services in South Africa has been substantial, with a 26\% decrease in Xpert tests performed in 2020 [54]. No data have been published yet on the impact of COVID-19 on child and adolescent TB services, but a dramatic decline (almost 50\%) in bacteriologically confirmed TB has been observed in children presenting to hospitals in the Western Cape province (unpublished data presented at The Union conference, in 2021, by HS Schaaf et al.).

The actual burden of TB in children and the case notification gap are unknown since the national TB prevalence survey excluded children. Quantifying the pediatric burden more accurately using tools appropriate for children needs to be prioritized in the investment case to ensure that the limited resources are efficiently and effectively directed for impact. Establishing a national "Child and Adolescent TB Working Group", e.g., as part of the multisectoral South African TB Think Tank [55], which advises the NTP to advocate for the needs of children and adolescents in South Africa will be an important step toward addressing some of these translational challenges. One of the first tasks of such a working group should be to update the national pediatric TB guidelines (2013) to align with updated WHO recommendations (2021) and operational guidance for implementation. Comprehensive and regular training for all healthcare workers working in TB and in maternal, child, and adolescent health services could greatly improve integration and care. Decentralized models of care for treatment of TB disease and TPT, such as through home-based care or ward-based outreach, could provide more family-centered options to effectively prevent, diagnose, and treat TB in children and adolescents. Active engagement with civil society organizations will help further create awareness and should involve child and adolescent TB ambassadors and their families, who can be the voice of their peers and advocate for their specific needs.

\subsection{Indonesia: Challenges to TB Detection for Children in the Time of COVID}

The COVID-19 pandemic is having a massive impact on health services in Indonesia. The first case of COVID-19 in Indonesia was detected in March 2020, and, as of end November 2021, a total of 4,256,409 people have had SARS-CoV-2 infection confirmed, and 143,830 have died [56,57]. The pandemic has impacted the utilization of healthcare services in Indonesia, with a 70\% decrease in non-COVID-19 healthcare service delivery from January to September 2020 [58]. This abrupt reduction was mainly because most health facility resources were diverted to the COVID-19 response, people's fear of exposure to SARS-CoV-2 at health facilities, and to the policy decision by clinic facilities to reduce service time and delay elective care [59].

Indonesia has the second highest number of $\mathrm{TB}$ cases annually in the world, as shown in Table 1. However, children and adolescents are often neglected in the response to TB control, with particular challenges for case detection highlighted by the difficulty to confirm the diagnosis microbiologically, as well as a major case notification gap, even when cases are 
diagnosed [60]. The COVID-19 pandemic has had a direct impact on TB control, including reversing recent efforts by the Indonesian NTP, to improve detection and treatment of child TB; the 70,341 reported child TB cases in 2019 was a 15\% increase compared to 2018 . However, only 32,930 child TB cases were reported in 2020, a 53\% reduction from the previous year and a return to numbers reported in 2016, when around 35,000 child TB cases were reported. Of 34 provinces in Indonesia, only two (Papua and West Java) provinces successfully reached the target for child TB case finding.

In the Mimika district of the high-incidence province of Papua, TB case finding activities was also affected by the pandemic. In 2020, the number of presumptive child TB cases fell by $38 \%$, and child $\mathrm{TB}$ case notifications fell by $21 \%$. However, the proportion of children among all presumptive TB and reported TB cases remained constant, at $12 \%$ and $21 \%$, respectively. The number of children who died during TB treatment increased by $116 \%$ during the pandemic, which contributed to a fall in treatment success rate among child $\mathrm{TB}$, from $77.5 \%$ in 2019 to $72.0 \%$ in 2020 . It is plausible that co-infection with COVID-19 and delayed access to healthcare were contributing factors (unpublished data, T Lestari).

Diagnosis remains a key challenge. While smear microscopy and/or Xpert MTB/RIF assay were performed in $54 \%$ of presumptive child $\mathrm{TB}$ cases, only $7 \%$ children treated for TB in 2020 were bacteriologically confirmed, and just 3.3\% among young $(<5$ years) children (unpublished data, T Lestari). The challenges also affect detection of drug-resistant TB. Only 84 (1.1\%) of 7961 bacteriologically confirmed drug-resistant TB cases in 2020 were children, and only 33 (39\%) of them were enrolled on treatment [61]. Extrapulmonary TB constituted about $28 \%$ of all child TB cases in Mimika, with mainly clinical diagnosis due to limited health resources to collect and test appropriate specimens (unpublished data, $\mathrm{T}$ Lestari). Sputum induction was commonly used for diagnosis in a hospital setting, but this aerosol-generating procedure is associated with particular risk in the context of the COVID-19 pandemic. The use of stool Xpert has been recommended based on supportive evidence from a multicenter study conducted in Indonesia. However, uptake of this new recommendation is very limited, with training and supervision required. In those not bacteriologically confirmed, major challenges remain with clinical diagnosis.

The last national child TB guideline was published in 2016 and is currently being updated. TPT is a key recommended strategy to prevent to TB disease in high-risk groups, such as young child ( $<5$ years) contacts or people living with HIV of any age. Since 2020, the NTP has extended TPT recommendations to all eligible household contacts, including adolescents. Six months of isoniazid preventive therapy remains the most common TPT regimen in Indonesia, but, in 2021, the NTP began to provide shorter TPT regimens of $3 \mathrm{RH}$ and $3 \mathrm{HP}$. The NTP has set a target to provide TPT to 49,222 young child contacts in 2020 , which is $40 \%$ of the estimated eligible number. However, the coverage remains very low (Table 1). A project in the Mimika district, in the Papua province, started in 2017 [62], increased the uptake of TPT for young child contacts five-fold by 2019, but this has been negatively impacted by the COVID-19 pandemic.

\subsection{Papua New Guinea: Addressing Challenges in a High-Burden Child TB Country}

In Papua New Guinea (PNG), TB in children constitutes around a quarter of all TB cases reported to the NTP [63]. The reasons for such a high proportion compared to other countries is due to a number contributing factors that include population demographics (children make up a high proportion of the population); under-detection and reporting of adult TB; a high prevalence of risk factors for child TB, such as malnutrition and high rates of infection; and reliance on clinical diagnosis. Major challenges exist for bacteriological confirmation, and a lack of diagnostic skills in some health workers results in both overdiagnosis and underdiagnosis. Xpert is increasingly available in PNG but is still limited to the major provincial centers [64]. Currently, more than 95\% of child TB is clinically diagnosed, and, even if respiratory specimens are available, the yield of Xpert for PTB is low. Many healthcare workers lack training in child TB management in PNG. Moderate to 
severe malnutrition is common in children with TB and adds challenges to diagnosis, as well as risk for worse outcomes.

Treatment success for child TB remains below target, with more than $30 \%$ of child TB lost to follow-up [63]. Except for the National Capital District, provinces in PNG do not have specific clinics to follow up child TB, and caregivers are not properly supported. PNG was one of the first countries to introduce child-friendly fixed-dose formulations to improve treatment in young children managed at Port Moresby General Hospital [65]. Recent progress has also been seen in both diagnosis and treatment of child TB in Port Moresby, under a TB/HIV project which supports additional child TB focused human resources, tools, training and transport. Healthcare workers were trained and sensitized to detect child TB, perform gastric aspirate and other specimen collection for bacteriological diagnosis, treat patients, and provide treatment support. This improved model of child TB care needs to be expanded to other provinces. Due to the geography of PNG being mountainous with many islands, decentralization of health services to the provincial level has long been recognized as necessary.

The COVID pandemic has greatly affected delivery of TB services due to restricted travel and reduced access to health facilities, including shutdowns of clinics or repurposing of services, such as human resources and deploying Xpert for SARS-CoV-2 diagnosis. As a result, child TB notifications have fallen, while treatment interruptions and loss to follow-up have increased.

Priorities to improve child TB response are identified in the National TB Strategy and include increasing case detection and susceptibility testing for all children with TB, increased treatment success for all child TB, and improved programmatic response for child TB. Addressing these priorities will be achieved through interventions that expand and decentralize activities for diagnosis, treatment, contact evaluation, and prevention. These will include procurement of diagnostic equipment; training for healthcare workers, including on the use of gastric aspirate, fine-needle aspiration, and other procedures; and updating and dissemination of all guidelines, algorithms, and standard operating procedures. Interventions to increase treatment success and prevention for child TB include: expansion of child TB treatment, including child-friendly formulations and all-oral regimens for drug-resistant TB; contact evaluation and TPT through community TB workers with implementation of integrated patient and family education and counseling secessions [66]; expansion of treatment facilities with nutritional support for all child TB patients; and identification and training of a provincial child TB focal person to support training of healthcare workers on child TB management. Additional Global Fund support provides transport and food incentives for children and families of drug-resistant TB patients.

Interventions to strengthen technical and managerial capacity for child TB includes the recruitment of a national child TB focal person who will liaise with PNG Pediatric Society and will identify and train child TB focal persons based at the provincial level. The PNG Pediatric Society and pediatricians in the National TB Technical Working Group have long supported NTP activities. PNG has approved and updated child friendly-treatment regimens for TB treatment and TPT and has recently contributed to the Guidelines Development Group involved in the recent update of the $\mathrm{WHO}$ child and adolescent TB guidelines.

\subsection{Mongolia: Major Challenges for TB Services, Including for Children and Adolescents}

TB services for children and adolescents in Mongolia face a wide spectrum of challenges at all levels. These include a lack of capacity at the ground level to volatile political landscapes at the leadership level. Mongolia is a large, sparsely populated country, and health services for TB are overly centralized to the capital, Ulaanbaatar, while the rest of the country is relatively neglected. There is a widespread shortage of trained and capable staff to provide TB care and services. According to 2015 NTP reports, about $50 \%$ of personnel working in TB were already at retirement age [67]. Existing staff are overloaded with excessive workload, despite being in a high-risk and low-paying job. There are inadequate policies and a lack of coordinated actions at the levels of planning, training, working condi- 
tions, and performance management. Mongolia has recently been included in the WHO list of 30 high-burden MDR TB countries, in 2021 [15], with notification rates remaining very low-at about $30 \%$ of those estimated in the last decade [67]. A national survey reported that the majority $(68 \%)$ of TB patients in Mongolia experience "catastrophic" treatment costs, and the individual, family, and health systems costs are even greater for patients with MDR TB [68]. The challenges are currently magnified by the COVID-19 pandemic, with active case finding activities decreasing fourfold, almost $2 \%$ increase in TB mortality in 2020 compared to 2019 [69].

The Mongolian NTP has restructured with six different managers in the last decade, and there are only two specialized pediatric TB clinicians nationwide. Decision-making is greatly limited by frequent changes in leadership, which hinders political will and commitment to achieve programmatic goals. Leadership issues have recently been highlighted by the inability to keep pace with rapidly changing WHO TB guidelines. In response to the shortage of competent healthcare workers for TB services, the government of Mongolia shortened the duration of TB residency training from two years to nine months, resulting in an influx of TB clinicians. In 2018-2020, the TB project of the Global Fund has supported 28 clinicians to specialize in TB, and, of these, $89.3 \%$ are already working in TB. However, the abbreviated training does not include any or sufficient time allocated to training in child TB. Human resource policies and training need to address long-term needs, and pediatricians need to be included in trainings on TB.

TB infection is common in Mongolian children; exposure in households and schools is common [70,71]. A pilot project on screening and management of household contacts of MDR TB cases in 19 sites of Mongolia demonstrated that 17 (5\%) of 349 contacts developed TB (unpublished data, B Tsogt), higher than reported to the NTP in 2019 [67]. It has also shown that there is a disconnect between TB and child health services, as well as a major lack of confidence and competence in the diagnosis of TB in children. District TB clinicians who are expected to provide services for child TB should receive training that would enable every TB dispensary to have at least one trained TB clinician to overcome the diagnostic challenges in children. The current shortage of child TB expertise leads to delays in diagnosis and treatment initiation, as well as a lack of implementation of household screening and TB prevention. NTP data in 2020 [69] reported that 76\% of child TB was lymph node TB, which highlights the difficulties that health workers are having to diagnose the more common pulmonary TB. On the other hand, there is also overdiagnosis with CXR in healthy children with a positive TST [69]. In the context of screening and management of household contacts of people with MDR TB, this has been noted to lead to unnecessary hospitalization and treatment of children with second-line TB medications.

\subsection{Vietnam: Where Are the Child TB Cases?}

Vietnam is listed as one of the world's 30 high-burden TB countries, with almost 100,000 people reported with TB in 2020, of an estimated 172,000 incident cases [4]. According to the Vietnam NTP, there should be between 10,000 and 20,000 child TB cases annually. The annual risk of TB infection in school-aged children was previously estimated to be $1.7 \%$, although more recent evidence from a mainly rural setting suggests that this is lower in young children [72,73]. However, only $1.5 \%$ of reported TB cases were children (<15 years); of the 1404 cases in 2020, two-thirds were older children (5-14 years). The proportion of child cases of MDR/RR TB was even lower, at 17 cases or $0.5 \%$ of all MDR TB in 2020. Therefore, the diagnosis and notification of pediatric TB remain significant challenges in the country.

Neonatal BCG vaccination is included in the Expanded Program on Immunization, and coverage has been at a high level since 2009. In 2019,95\% of neonates in Vietnam received $B C G$, though vaccination rates were lower for children who were born in rural areas, in ethnic minority communities, or to mothers with low education [74]. The high BCG coverage will impact on severe disease in young children, but clinical diagnosis is an ongoing challenge as a reliance on bacteriological confirmation results in under-detection, 
especially among high-risk young children [75]. Of pulmonary TB cases in children, the sputum smear-positive cases were mostly in older children. Though Xpert is now recommended for bacteriological confirmation in children, access is limited.

The NTP's child TB Working Group has been expanded to include new international partners. The group has recently developed and completed guidelines on childhood TB management, training, and communication materials. There is a lack of knowledge on child TB diagnosis among healthcare staff, as well as inadequate collaboration between child health and TB services. Most TB hospitals do not have a pediatric department. In 2020, the NTP organized training courses for health workers on the diagnosis and management of childhood TB for 63 provinces. The network that connects the National Pediatric Hospital with provincial hospitals has been strengthened for direct or online joint diagnosis consultation and referral. In 2020, a pilot study on Xpert testing of stool in children was started. Treatment regimens are consistent with WHO guidelines. The rate of treatment completion or cured among all treated children was $67 \%$. It was higher for those evaluated as treatment cohort in 2019, but around 30\% of children were not evaluated for a treatment outcome.

A national guideline on TPT implementation was revised in 2020, providing guidance for contact investigation and TPT among young child ( $<5$ years) contacts or children living with HIV without TST administration. In 2020, the NTP organized training courses for health workers on TBI management for children in 25 high-burden provinces. After ruling out active TB, eligible children are offered either $6 \mathrm{H}$ or $3 \mathrm{RH}$ as TPT, while children aged 2 years or older have an additional option of $3 \mathrm{HP}$. The NTP has supported the roll-out of a community-based contact management program since 2012. In the second half of 2020, 3552 young child contacts were initiated on TPT, which represents $54 \%$ of 6617 eligible children in the pilot program. However, the overall coverage of TPT for young child contacts in 2020 reported to the WHO was only 5\% [15]. There is an ongoing challenge of limited access to TST tests among children 5 years and older for TBI diagnosis, under-notification of TPT coverage, uptake, and completion.

\subsection{French-Speaking African Countries: A Focus on Child Contact Management}

TB contact screening and management is a key strategic intervention in the fight against TB. This intervention aims to include active case-finding among contacts with prompt treatment to improve outcomes and reduce ongoing transmission with the provision of TPT to eligible contacts to reduce risk of TB disease. While this strategy has been recommended for many years, using at least six months of isoniazid preventive therapy, it is rarely implemented in French-speaking African countries. There is evidence from a randomized trial on the safety of four months of daily rifampicin that included children from Guinea and Benin [25]. A recent project supported by The Union demonstrated high uptake and completion, as well as effectiveness and safety, of a shorter TPT regimen using the child-friendly fixed-dose formulation of rifampicin-isoniazid in urban settings in four countries [76].

The Contributing to the Elimination of Tuberculosis in Africa (CETA) project is now being implemented within routine activities by NTPs in eight francophone African countries (Benin, Burkina Faso, Cameroon, Guinea, Niger, Central African Republic, Senegal, and Togo) with support by The Union. The first component of this project enabled the implementation of TB contact investigation with a focus on several vulnerable groups, including young child contacts. At the beginning of the CETA project, 150 Basic Management Units were identified as pilot sites in the eight countries. The tools to implement the activity were developed, and a national training was organized for nurses and community healthcare workers. Preliminary results report that, between October 2020 and March 2021, 4540 home visits were carried out, 2940 children under 5 years were initiated on TPT, and 89 were treated for active TB (CETA Activities Report 2021, unpublished data, KGK).

Project implementation has identified several major challenges. Despite the training, some countries note a low level of involvement and proficiency of community healthcare 
workers. Some countries experience a high turnover of trained staff. There are difficulties in effectively referring children to evaluate for TB disease before initiation of TPT. There are particular difficulties of access to populations who live in areas considered unsafe. The project has also highlighted the lack of coordination between child health and TB services, as well as the refusal of some parents to agree to TPT for their healthy child. Finally, the COVID-19 pandemic has reduced attendance to clinics for referral assessment or follow-up [77].

In order to scale up this project activity, several actions are necessary that can be quickly implemented. The national policy on community healthcare workers should be reviewed and updated to include TB contact investigation in the package of the activities of community healthcare workers. The capacity of healthcare providers to detect and manage child TB needs strengthening, with collaboration between the NTP and pediatric services. The development of a communication and advocacy plan is required to improve community education and engagement, and financing, including that for home visit costs, could be included in Global Fund grants.

In terms of future perspectives, the implementation of a simple clinical algorithm suitable for use by community healthcare workers and nurses would help to detect or eliminate active TB in child contacts. The activity should be digitalized in real time, and the use of digital chest $X$ ray with computer-aided detection should be evaluated [77]. Many countries recommend a test for infection before TPT initiation, as does the WHO, for older child contacts who are HIV-negative; therefore, a rapid test for infection would be a real advantage. Finally, there are currently no interventions that specifically support adolescents with TB in French-speaking African countries. This component remains to be developed and should be prioritized by NTPs in future grants.

\subsection{Zambia: Challenges for NTP and Action to Strengthen Child and Adolescent TB Services}

Zambia has a high prevalence of tuberculosis and is listed as a high-burden country for TB, TB/HIV, and MDR/RR (Table 1) [4,78]. Of the estimated nearly 60,000 annual TB cases, a third are undiagnosed or unreported. The case detection gap is higher among children, contributing only $6 \%$ of the annual caseload, while coverage for contact screening and TPT for young child contacts remains a challenge [79]. TB/HIV coinfection rates are high in adults and children, but there has been a sustained improvement in TPT coverage for people living with HIV. The burden of MDR TB in children remains poorly undefined.

Key national priorities for addressing child TB include: addressing the case detection gaps, sustained improvement in treatment outcomes, rolling out TB prevention services, and addressing the threat posed by the COVID-19 pandemic. Tackling the case detection gap requires addressing the perennial diagnostic challenges in child $\mathrm{TB}$, which restricts case detection to district, regional, or tertiary facilities, thereby limiting access to care. Low notification rates have been attributed to low index of suspicion, underdiagnosis, and under-reporting of TB in children within the health system [80]. Autopsy studies of Zambian children conducted over a decade apart have shown that TB is persistently a frequent cause of death in children with respiratory illness that is not often detected antemortem $[81,82]$. Therefore, implementing systematic screening and creating clinical awareness with emphasis on the use of clinical tools to improve case detection and early treatment is a priority to reduce TB-related morbidity and mortality in Zambian children.

The NTP will require investing more in healthcare worker capacity building, as well as improving access to diagnostic tools. This includes access to old tools, such as CXR, as well as the adoption of new tools, that can be used at lower-level facilities, such as the use of Xpert in stool or detection of LAM in urine for target populations, to tackle the case detection gaps of both drug-susceptible and drug resistant TB. Improving access to treatment through decentralization of care, ensuring availability of child-friendly formulations, and strengthening linkage to HIV care for children living with HIV are all essential elements to sustain good treatment outcomes and achieving the End TB targets. 
The implementation and scale-up of prevention, through increasing coverage and completion of TPT for eligible child TB contacts, is another key priority. Low community awareness, healthcare provider perceptions, supply chain problems, and policy implementation gaps have been recognized as barriers that must be overcome for successful IPT implementation in the country $[79,83]$. To address these policy-practice gaps, the NTP has provided policy guidance on the systematic implementation of TPT, while setting coverage targets for child contacts and PLWH, ensuring provision of commodities, adopting shorter TPT regimens, addressing health worker and community barriers, providing trainings and mentorship of healthcare providers, and engaging civil societies.

The COVID-19 pandemic threatens to derail gains made in the provision of TB services. Measures introduced to contain COVID-19 had an impact on the delivery of all public health services, including TB care [84]. This has necessitated the adoption of approaches that minimize the challenges that people with TB face in accessing services and care [85]. Measures implemented to mitigate the impact of COVID-19 include providing national guidance on the maintenance of TB services, adapting procedures to avoid, where possible, frequent contact with health services, including telephone follow-up, co-messaging of TB and COVID-19, and the use of community agents to support care. The NTP adopted the use of a virtual platform to hold weekly meetings that linked all health facilities in the country. This allowed tracking of performance of TB services against targets and helped in identifying areas for support that were being impacted during COVID upsurges.

Sustained political will is critical to address the identified priorities. The NTP has updated its National TB Strategic Plan to align with the Global End TB goals to capture and address child TB interventions. This has been an inclusive process that engaged all key stakeholders, including the National TB/HIV technical working group, the childhood TB technical working group, civil societies, non-governmental organizations, and other partners, involved in TB services. The outputs of the National Strategic Plan aim to address some of the policy gaps in adolescent TB, integration with maternal and child health services, TB/HIV services, improving access to treatment, and sustaining good treatment outcomes.

\subsection{Uganda: Addressing Programmatic Challenges to Improving TB Services for Children and Adolescents}

The WHO lists Uganda as a high-burden country for TB and TB/HIV. Over recent years, the country has documented a steady improvement in child and adolescent TB case finding (currently at $12 \%$ of the total case load) and treatment coverage (Table 1) with support from key stakeholders. Despite significant investment into in-service capacity building, gaps remain that emphasize the need to evaluate and review implementation to address the "know-do gap". There are opportunities that can be leveraged to bolster the delivery of quality patient-centered TB services for children and adolescents [86].

There have been recent efforts to develop training, tools, and job aides to support the lower-level health facilities and community health workers, which resulted in increased case detection, improved treatment outcomes, and improved access to TPT for contacts [86,87]. However, updated information on the programmatic management of TB in children has not been widely disseminated, including within referral hospitals, training institutions, and the private sector. In addition, there is limited access to chest radiography, often due to non-functionality or out-of-pocket cost for the service.

Due to diagnostic delays, children with TB, especially those living with HIV, commonly present with complicated TB, partly contributing to sub-optimal treatment outcomes. Dispersible child-friendly formulations are now available for fixed-dose combinations of first-line drugs, except for dispersible ethambutol $(100 \mathrm{mg})$. Case notification of child TB is inconsistent, and treatment follow-up is particularly challenging, for children within the migrant populations, such as pastoralists. There are major gaps in detecting and managing drug-resistant TB due to limited health worker capacity and few options for child-friendly formulations of second-line drugs. 
Implementation of TB contact evaluation has been inconsistent due to limited dissemination of the approved operational guidelines, lack of tools, and insufficient focused funding support. Health workers often lack the clinical skills or confidence to exclude TB among contacts before providing TPT. Concerns about potential toxicity and resistance development have hindered TPT uptake, especially among under-five contacts. This is coupled with the general community perception that TB does not affect children, contributing to a low demand for the service.

There is an ongoing need to build capacity, including equipping health facilities, training, mentorship, and supervision. The DETECT child TB project showed that effective training and health worker support to overcome these misperceptions and build confidence and capacity increased case detection more than two-fold [87]. The model is currently being scaled up to 50 districts. The NTLP transitioned to using age disaggregated data for child TB reporting and recently initiated the phased introduction of e-case based surveillance for TB. Once scaled up, this provides an opportunity for real-time reporting; the current coverage is less than $10 \%$ of the TB treatment facilities.

Challenges within the private sector are the limited engagement of clinicians and that the costs of diagnostics are not affordable for the majority of the population. Many private facilities have transitioned to electronic medical records, yet paper-based documentation is the main platform for the national health information system. The limited access to a sample transportation system, coupled with delays in sample pick-up and delivery of results, are barriers to the use of Xpert MTB/RIF for the private facilities.

The new patient-centered National Strategic Plan, and TB Multisectoral Accountability Framework, provides opportunities for enhancing child TB service delivery, including adaptation and scale-up of successful innovations. While the policy favors the clinical diagnosis of TB, especially among young children, TB services must be further decentralized with support for screening, treatment availability, and follow-up at the peripheral facility level (level II), and with linkages up to the referral, specialist facility (level V). Further, there is currently inconsistent targeted mentorship and supervision, partly due to limited resources, such as limited numbers of skilled mentors. The delay in finalizing and disseminating the updated school health policy has hindered the implementation of standardized TB-focused interventions in schools. In Uganda, the school health policy is housed under the education sector, which calls for enhanced approaches to engage the other key players.

The COVID-19 pandemic has negatively impacted case detection. Many health workers have focused on symptom screening for COVID-19, and there was a heightened stigma for TB during the initial phase of the COVID pandemic. The "stay at home" message targeting people with respiratory symptoms, coupled with travel restrictions, meant that children with TB-related symptoms were more likely to be kept at home. To mitigate the negative impact of COVID on TB service delivery, the MOH/NTLP developed guidance to ensure continuity of care, which guided the implementation of innovations in collaboration with stakeholders.

\subsection{Timor-Leste: Recent Attention to Childhood TB}

Timor-Leste has one of the highest TB incidence rates in the Asia-Pacific region, with an estimated annual incidence that has ranged between 498 and 508 per 100,000 population per year [15]. The prevalence of drug-resistant TB is low, with rifampicin resistance detected in only $1.3 \%$ of cases included in a recent drug resistance survey [88]. Under-detection of TB is a major challenge for all age groups, exacerbated by geographical challenges with remoteness and terrain, limited knowledge and understanding within the community, difficulties with access to radiologic and laboratory diagnostic testing, and variability in diagnostic approach across the country. More than $80 \%$ of TB patients in Timor-Leste experience catastrophic costs in relation to their TB diagnosis and care [89]. In 2020, only 51\% of estimated incident cases were detected and started on treatment [15]. 
It is likely that there is a very high burden of TB in children and adolescents in Timor-Leste. Approximately $40 \%$ of the population is aged less than 15 years, and malnutrition is common, with approximately $49 \%$ of young children $(<5$ years) being moderately or severely stunted [90]. Anecdotal experience of pediatricians working in the national referral hospital (Hospital Nacional Guido Valadares) in Dili includes frequent encounters with severe manifestations of disseminated TB in children. However, only $8 \%$ of new and relapse TB case notifications in 2020 were in children aged less than 15 years, as shown in Table 1 [15]. Fewer cases are diagnosed in the 0-4-year age group than the 5-14-year age group. The proportion of reported TB cases that are children varies between municipalities, making up less than $5 \%$ of diagnosed cases in some settings.

Children living outside the capital Dili or other major centers are less likely to get access to chest $\mathrm{x}$-ray or molecular testing with Xpert. While most cases are clinically diagnosed, there is a general reluctance to diagnose TB and commence treatment without laboratory confirmation and/or involvement of a pediatric specialist. Access to pediatricians outside of the six referral hospitals is limited, and there are systemic, as well as patient and family level, barriers to transferring patients to hospital unless they are acutely and severely unwell.

The NTP has led on initiatives to improve case detection of TB in adults and in children, supported by the WHO and other partners. Timor-Leste's first Guidelines for the Management of Tuberculosis in Children were developed by the NTP in 2016 and were accompanied by a series of training events that included clinicians from all 13 municipalities of Timor-Leste. Xpert testing is recommended as the first-line laboratory test for children with presumptive TB. The recently revised Comprehensive TB Guidelines for NTP and the NTP's National Strategic Plan for Ending TB 2020-2024 have prioritized increasing access to chest $x$-ray and Xpert for diagnosis, as well as the importance of supporting and empowering clinicians to make clinical diagnoses of TB in children. A national TB prevalence survey is planned for 2022, and, while it will not enroll children, it will provide the most accurate estimates to date of the burden of TB in Timor-Leste, which can be used to measure progress in case detection and treatment over the coming years.

The COVID-19 pandemic has significantly and negatively impacted care-seeking behavior in Timor-Leste, and TB case detection rates have dropped as a result. However, it has also led to a significant investment in increasing access to GeneXpert testing for SARS-CoV-2, TB, and other diseases, with additional GeneXpert machines installed, and plans for at least one machine to be installed in all 13 municipalities of Timor-Leste by 2022. The COVID-19 pandemic has also illustrated the importance and potential effectiveness of household contact evaluation for airborne infectious diseases, such as COVID-19 and TB.

There is an urgent need to improve contact evaluation for TB cases in Timor-Leste, which can have an impact on increasing secondary case-finding and providing access to TPT. This is especially important for young child contacts, who frequently represent missed opportunities for the prevention of TB disease in Timor-Leste [91].

\subsection{Colombia: Challenges and Priorities for Change to Improve the Care of Children and Adolescents with Tuberculosis}

The number of cases and the quality of care for children and adolescents with TB in Colombia vary greatly by region due to socioeconomic disparities. Healthcare services in rural areas are precarious. Allotted budgets are insufficient and often further reduced by the corruption prevailing in the country [92]. The disarticulation of previously vertical public health programs (including TB) is a consequence of administrative decentralization and of the municipalization of health programs [93]. Additional barriers include bureaucracy related to health insurance programs, as well as fragmentation of care [94]. Physical access to healthcare facilities is often limited due to the presence of illegal armed groups. As a result of decades of violence in rural areas, Colombia has the most internally displaced persons in the world, estimated at 8.3 million individuals, which is more than $16 \%$ of the national population. In addition, 1,731,000 Venezuelan refugees have migrated to Colombia [95]. Furthermore, expertise in child and adolescent tuberculosis is limited, and 
the retention of trained healthcare professionals is poor due to job insecurity and poor salaries. Finally, TB is still highly stigmatized in Colombia, with considerable discrimination toward sufferers.

The aforementioned challenges demand the strengthening of both the NTP and local programs. These should be better integrated with other child health programs and should work in coordination with various entities to guarantee children's rights to healthcare. Furthermore, TB care teams need to be trained (and to receive continuing education) in child TB, to have job security (to ensure continuity), to have adequate resources to implement current standards of care, and to work in partnership with local communities.

In Colombia, the incidence rate of TB has been increasing, estimated to be 37 cases per 100,000 population for 2020 [15]. Only 35\% of estimated child TB cases are detected, and even less during the COVID-19 pandemic; 328 cases were reported in children in 2020 compared to 404 cases in 2019. To assure timely TB care through and after the COVID-19 pandemic, it will be necessary to effectively support local TB control programs to achieve more opportune active case finding amongst both adults and children, as well as more timely notification of detected cases.

Delayed diagnoses of TB in children and adolescents are not uncommon [96]. There is limited detection of TB disease at outpatient clinics offering primary care. Reasons include limited knowledge of TB and misdiagnosis with other diseases, which leads to a high percentage (58\%) of cases being diagnosed at the time of a hospitalization. When TB is clinically suspected in a child, the guidelines of the NTP recommend CXR, a test for infection, and to seek bacteriological confirmation [97]. However, the availability of laboratory diagnostics is inadequate, especially at PHCs, and, even when available, results are delayed. Consequently, presumptive diagnoses are often made based on clinical, radiological, and epidemiological criteria. In children with paucibacillary disease, treatment is often not initiated until the disease is advanced and/or complications have developed. Treatment success was reported to have been attained in $78.3 \%$ of children, but sequelae are not reported. There are difficulties with treatment adherence and support, with follow-up especially challenging in communities that are geographically isolated. Some indigenous peoples reject treatment for cultural reasons.

To overcome these challenges, there should be no barriers to access comprehensive care for early diagnosis of TB exposure, infection, or disease, especially in high-risk vulnerable populations. It is necessary to shorten the time intervals between the onset of symptoms, diagnosis, and initiation of treatment. This requires NTP to provide technical assistance to local TB care teams and to decentralize laboratory capacity with molecular diagnostics. The NTP must assure uninterrupted availability of TB medications without barriers, the mutual commitment between the NTP and the patient that takes into account cultural aspects and allows for adequate treatment support. Lastly, the support of civil society organizations is required to improve treatment administration and adherence, especially in the indigenous population.

Contact screening is implemented in only a minority of infectious TB patients, and TPT for eligible at-risk children is rarely initiated or completed. There is limited understanding of TBI amongst healthcare professionals and laypeople, compounded by a low perception of the risk in children. Some communities and parents are reluctant to have their otherwise healthy children evaluated for TB exposure. Testing for TBI is very limited with persistent shortages of tuberculin and a scarcity of personnel trained in tuberculin skin testing. Interferon-gamma release assays are only available in large cities and are very expensive. According to the NTP, in 2020, TB contact investigations resulted in 1,448 children receiving TPT for confirmed or presumptive TBI; only $185(12.8 \%)$ were less than 5 years of age. Access to testing for TBI and CXR is required [98]. A family- and community-based approach needs to be developed in order to promote awareness of TBI and the value of prevention with TPT regimens that are shorter than isoniazid preventive treatment. 


\section{Common Challenges and Way Forward}

Attention to the needs of children with TB disease or with TB infection who live in TB-endemic, often resource-constrained settings has increased over the last decade, and, in recent years, adolescents have also received a greater and deserved focus [6,19]. Yet, despite the increased advocacy, greater inclusion in guidelines and policy and research, and the availability of child-friendly prevention and treatment, it is estimated that more than 650 children still die of TB every day [4]. Therefore, TB is an important cause of morbidity and mortality in children and adolescents globally, despite being treatable and preventable.

The country perspectives in this article provided by national pediatric TB experts from $\mathrm{TB}$ endemic countries all identify the notification gap as a challenge-missed opportunities to detect and treat, as well as under-reporting of child and adolescent TB, who are diagnosed. Effective first-line treatment is widely available and effective, including child-friendly dispersible formulations, but the challenge is to make the diagnosis. Identified underlying drivers contributing to under-detection were the shortage of trained staff, lack of access to diagnostic tools, reluctance to diagnose TB without bacteriological confirmation, and limited access to expertise at central hospitals. Child TB services and expertise tend to be strongly centralized, but most children and adolescents requiring TB treatment or TPT do not present, at least initially, to the specialized services, nor would most require referral if services were more decentralized [99]. All child TB working groups now recognize that strengthening diagnosis (clinical and bacteriological) is critical and needs to happen at all facility levels. The diagnosis and treatment of MDR TB in young children is consistently identified as a major challenge at all levels of the health system.

Despite almost universal recommendations for decades, implementation of TPT for child contacts remains well below targets [15]. Countries have variably adopted recently recommended TPT options (Table 2), but a huge policy-practice gap for the implementation of contact investigation is recognized. There is often a lack of integration between TB and child health services [14], which is now recognized by many as important to address in order to improve services for detection, treatment, and prevention. All countries have reported a significant negative impact of the COVID-19 pandemic on TB case detection and treatment outcomes, including increased mortality and loss to follow-up, as well as on services for prevention.

The importance of accurate surveillance data for both child and adolescent TB is recognized as critical [9]. Countries are increasingly able to provide age-disaggregated data and are introducing programmatic indicators for TPT along the cascade of care (Table 2). The need for data for real-time program monitoring and evaluation has been highlighted by multiple countries. Despite the availability of national guidelines and child-friendly treatment options in many countries, implementation of services remains sub-optimal due to inadequate training and surveillance systems, with high turnover of trained staff and low demand noted as underlying factors.

The WHO has published updated and consolidated guidelines for NTPs on the management of child and adolescent $\mathrm{TB}$, and the guidelines are supported by an operational handbook $[17,18]$. A number of the recommendations are directly relevant to the aforementioned needs: decentralized models of care, treatment decision approaches that can be used at all levels of care, strengthening laboratory diagnosis, including of MDR/RR TB, and updated treatment options, including those for TB meningitis and MDR TB, as well as including the recent TPT guidelines with dosage charts. The WHO guidelines and handbook are complimented by the timely report of the Defeat Childhood TB project, a multi-country assessment of childhood TB programm funded by the Elizabeth Glazer Pediatric AIDS Foundation and Unitaid, that calls national policymakers and world leaders to action [100]. The report outlines a framework consisting of seven key policy recommendations for NTPs to strengthen child and adolescent TB services (Figure 3). 


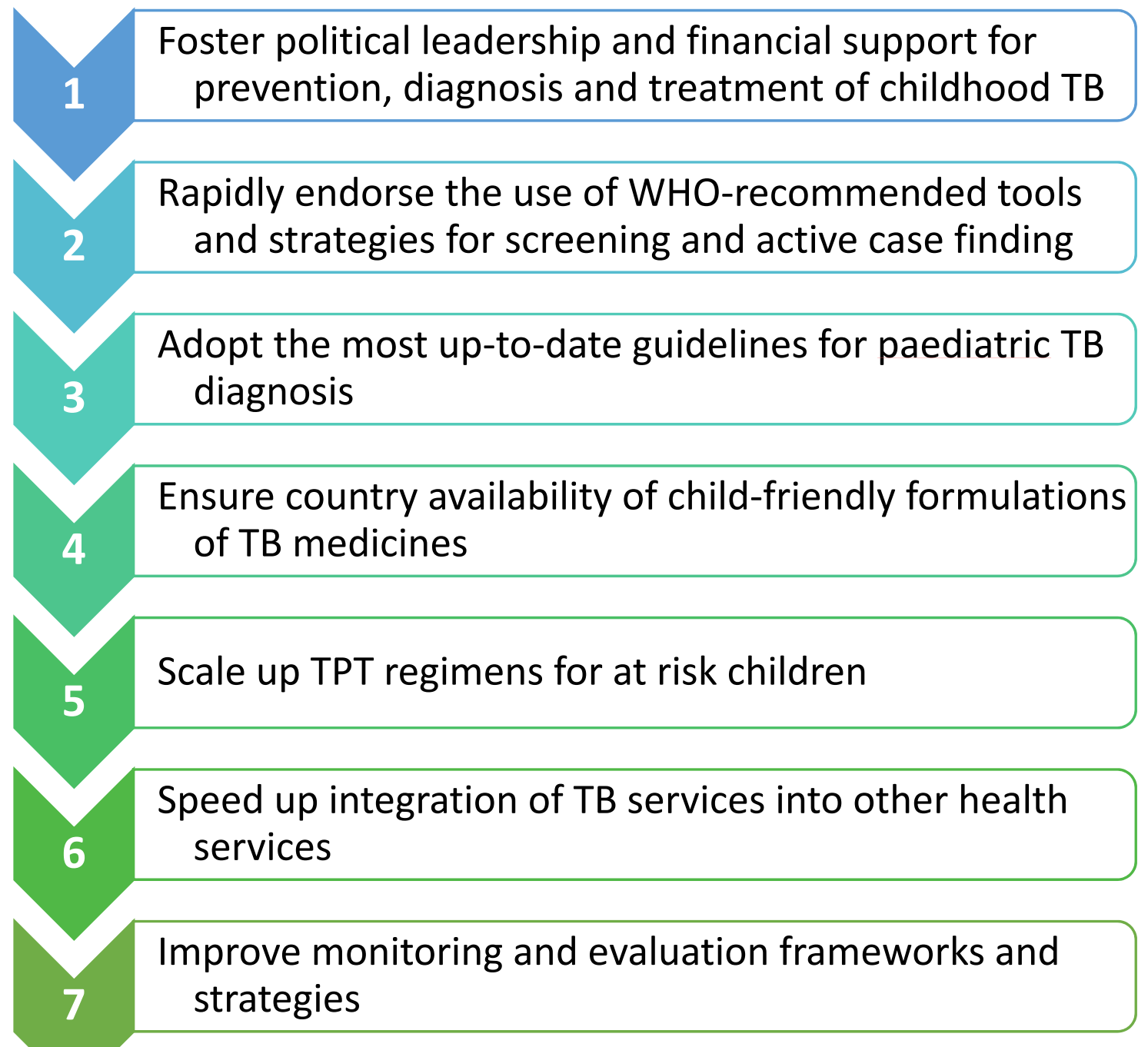

Figure 3. Seven key policy recommendations for NTPs as listed in the "Call to action to DEFEAT childhood TB." Adapted from Ref. [100]. These actions are consistent with the roadmap [14] and can guide child TB working groups to define the next steps to address remaining country-specific challenges to address the policy-practice gaps that this article highlights by providing detailed perspectives and country-specific updates from a wide range of settings, for the first time, on efforts to address child and adolescent TB.

Author Contributions: Conceptualization, K.d.P., S.M.G.; writing-original draft preparation, K.d.P., B.M.A.G., S.K.K., R.T., T.L., M.K., B.T., T.A.N., K.Z., C.C., M.P.S., C.L., J.R.F., C.M.P.-V., K.G.K., S.M.G.; writing-review and editing, K.d.P., B.M.A.G., S.K.K., R.T., T.L., M.K., B.T., G.D., E.P., T.A.N., L.N., L.M., H.S.S., A.C.H., A.M.d.O.R., A.C.C.C., C.A.A.C., C.C.S., D.G.D.O., F.D.C., L.R.V., M.d.F.P.S., N.B.H., P.H.P., A.A.F., D.A., G.B., A.R.O., T.S., A.C., A.K.K., B.N.A.P., A.S.M., A.M.B., A.S., G.H., H.G., N.F., B.G., M.F.D., O.M., M.D., K.Z., C.C., M.P.S., H.L., S.T., J.P.D., C.L., M.d.S., J.R.F., M.A.-L., C.M.P.-V., K.G.K., S.M.G. All authors have read and agreed to the published version of the manuscript.

Funding: K.d.P. is supported by the Fogarty International Center of the National Institutes of Health under Award Number K43TW011006. The content is solely the responsibility of the authors and does not necessarily represent the official views of the National Institutes of Health.

Institutional Review Board Statement: Not applicable.

Informed Consent Statement: Not applicable.

Data Availability Statement: Not applicable. 


\begin{abstract}
Acknowledgments: We acknowledge the efforts of healthcare workers and National TB Program staff in the 19 countries featured who strive to improve care for children and adolescents with tuberculosis, as well as provide services for prevention.
\end{abstract}

Conflicts of Interest: The authors declare no conflict of interest.

\title{
References
}

1. Hsu, K. Should primary tuberculosis in children continue to be neglected? J. Pediatr. 1956, 48, 501-519. [CrossRef]

2. World Health Organization. The Stop TB Strategy. Building on and Enhancing DOTS to Meet the TB-Related Millenium Development Goals; World Health Organization: Geneva, Switzerland, 2006.

3. World Health Organization. Guidance for National Tuberculosis Programmes on the Management of Tuberculosis in Children. Stop TB Partnership Childhood TB Subgroup; World Health Organization: Geneva, Switzerland, 2006.

4. World Health Organization. Global TB Report 2020; World Health Organization: Geneva, Switzerland, 2020.

5. Call to Action for Childhood TB. Stop TB Partnership, Geneva, Switzerland. 2011. Available online: http://www.stoptb.org/ getinvolved/ctb_cta.asp (accessed on 12 October 2021).

6. Sandgren, A.; Cuevas, L.E.; Dara, M.; Gie, R.P.; Grzemska, M.; Hawkridge, A.; Hesseling, A.C.; Kampmann, B.; Lienhardt, C.; Manissero, D.; et al. Childhood tuberculosis: Progress requires advocacy strategy now. Eur. Resp. J. 2012, 40, 294-297. [CrossRef]

7. World Health Organization. Roadmap for Childhood Tuberculosis: Towards Zero Deaths: World Health Organization/The Union/Unicef/CDC/TAG/USAID/Stop TB Partnership; World Health Organization: Geneva, Switzerland, 2013.

8. World Health Organization. Guidance for National Tuberculosis Programmes on the Management of Tuberculosis in Children, 2nd ed.; World Health Organization: Geneva, Switzerland, 2014.

9. Seddon, J.A.; Jenkins, H.E.; Liu, L.; Cohen, T.; Black, R.E.; Becerra, M.C.; Graham, S.M.; Sismanidis, C.; Dodd, P.J. Counting children with tuberculosis: Why numbers matter. Int. J. Tuberc. Lung Dis. 2015, 19, S9-S16. [CrossRef] [PubMed]

10. World Health Organization. End TB Strategy; World Health Organization: Geneva, Switzerland, 2015.

11. Graham, S.M.; Grzemska, M.; Gie, R.P. The background and rationale for a new fixed-dose combination for first-line treatment of tuberculosis in children. Int. J. Tuberc. Lung Dis. 2015, 19, S3-S8. [CrossRef] [PubMed]

12. Graham, S.M.; Grzemska, M.; Brands, A.; Nguyen, H.; Amini, J.; Triasih, R.; Talukder, K.; Ahmed, S.; Amanullah, F.; Kumar, B.; et al. Regional initiatives to address the challenges of tuberculosis in children: Perspectives from the Asia-Pacific region. Int. J. Infect. Dis. 2015, 32, 166-169. [CrossRef] [PubMed]

13. Snow, K.J.; Sismanidis, C.; Denholm, J.; Sawyer, S.M.; Graham, S.M. The incidence of tuberculosis among adolescents and young adults: A global estimate. Eur. Resp. J. 2018, 51, 1702352. [CrossRef] [PubMed]

14. World Health Organization. Roadmap towards Ending TB in Children and Adolescents. World Health Organization/Unicef/ Stop TB Partnership/The Union//TAG/KNCV/The Global Fund/EGPAF/USAID/Unitaid; World Health Organization: Geneva, Switzerland, 2018.

15. World Health Organization. Global Tuberculosis Report 2021; World Health Organization: Geneva, Switzerland, 2021.

16. World Health Organization. Rapid Communication on Updated Guidance on the Management of Tuberculosis in Children and Adolescents; World Health Organization: Geneva, Switzerland, 2021.

17. World Health Organization. WHO Consolidated Guidelines on Tuberculosis. Module 5: Co-Morbidities, Vulnerable Populations and People-Centred Care. Management of Tuberculosis in Children and Adolescents; World Health Organization: Geneva, Switzerland, 2022; in press.

18. World Health Organization. WHO Operational Handbook on Tuberculosis. Module 5: Co-Morbidities, Vulnerable Populations and People-Centred Care. Management of Tuberculosis in Children and Adolescents; World Health Organization: Geneva, Switzerland, 2022; in press.

19. Moscibrodzki, P.; Enane, L.A.; Hoddinott, G.; Brooks, M.B.; Byron, V.; Furin, J.; Seddon, J.A.; Meyersohn, L.; Chiang, S.S. The impact of tuberculosis on the well-being of adolescents and young adults. Pathogens 2021, 10, 1591. [CrossRef]

20. World Health Organization. WHO Consolidated Guidelines on Tuberculosis-Tuberculosis Preventive Treatment; World Health Organization: Geneva, Switzerland, 2020.

21. Ministry of Health, Brazill; Secretaria de Vigilância em Saúd. Coordenação Geral de Vigilância das Doenças de Transmissão Respiratória de Condições Crônicas do Departamento de Doenças de Condições Crônicas e Infecções Sexualmente Transmissíveis. Sistema de Informação de Agravos de Notificação (SINAN); Ministério da Saúde: Brasilia, Brazil, 2021.

22. De Oliveira, M.C.B.; Sant 'Anna, C.C.; Luiz, R.R.; Soares, E.C.C.; Kritski, A.L. Contribution of Xpert MTB/RIF to clinical diagnosis in adolescents with tuberculosis in Rio de Janeiro, Brasil. Int. J. Tuberc. Lung Dis. 2019, 23, 1115-1121. [CrossRef]

23. De Oliveira, M.C.B.; Sant'Anna, C.C.; Luiz, R.R.; Kritski, A.L. Unfavorable outcomes in tuberculosis: Multidimensional factors among adolescents in Rio de Janeiro, Brasil. Am. J. Trop. Med. Hyg. 2020, 103, 2492-2500. [CrossRef]

24. Villarino, M.E.; Scott, N.A.; Weis, S.E.; Weiner, M.; Conde, M.B.; Jones, B.; Nachman, S.; Oliveira, R.; Moro, R.N.; Shang, N.; et al. Treatment for preventing tuberculosis in children and adolescents: A randomized clinical trial of a 3-month, 12-dose regimen of a combination of rifapentine and isoniazid. JAMA Pediatr. 2015, 169, 247-255. [CrossRef]

25. Diallo, T.; Adjobimey, M.; Ruslami, R.; Trajman, A.; Sow, O.; Obeng Baah, J.; Marks, G.B.; Long, R.; Elwood, K.; Zielinski, D.; et al. Safety and side effects of rifampin versus isoniazid in children. N. Engl. J. Med. 2018, 379, 454-463. [CrossRef] [PubMed] 
26. Sant'Anna, C.C.; Orfaliais, C.T.; March, M.d.F.; Conde, M.B. Evaluation of a proposed diagnostic scoring system for pulmonary tuberculosis in Brazilian children. Int. J. Tuberc. Lung Dis. 2006, 10, 463-465.

27. Carvalho, A.C.C.; Cardoso, C.A.A.; Martire, T.M.; Migliori, G.B.; Sant' Anna, C.C. Epidemiological aspects, clinical manifestations and prevention of pediatric tuberculosis from the perspective of the End TB strategy. J. Bras. Pneumol. 2018, 44, 134-144. [CrossRef] [PubMed]

28. Sant'Anna, C.C.; de Oliveira, M.C.B. The long-running issues of tuberculosis. Lancet Glob. Health 2021, 9, e1339-e1340. [CrossRef]

29. Tahan, T.T.; Gabardo, B.M.; Rossoni, A.M. Tuberculosis in childhood and adolescence: A view from different perspectives. $J$ Pediatr. 2020, 96, 99-110. [CrossRef]

30. India TB Report 2020; National Tuberculosis Elimination Programme, Ministry of Health and Welfare: New Delhi, India, 2020. Available online: https:/ / tbcindia.gov.in/showfile.php?lid=3538 (accessed on 29 August 2021).

31. Singh, V.; Parakh, A. What Is new in the management of childhood tuberculosis in 2020? Indian Pediatr. 2020, 57, 1172-1176. [CrossRef] [PubMed]

32. Singh, S.; Singh, A.; Prajapati, S.; Kabra, S.K.; Lodha, R.; Mukherjee, A.; Singh, V.; Hesseling, A.C.; Grewal, H.M.; Delhi Pediatric TB Study Group. Xpert MTB/RIF assay can be used on archived gastric aspirate and induced sputum samples for sensitive diagnosis of paediatric tuberculosis. BMC Microbiol. 2015, 15, 191. [CrossRef]

33. Kalra, A.; Parija, D.; Raizada, N.; Sachdeva, K.S.; Rao, R.; Swaminathan, S.; Khanna, A.; Chopra, K.K.; Hanif, M.; Singh, V.; et al. Upfront Xpert MTB/RIF for diagnosis of pediatric TB-Does it work? Experience from India. PLoS ONE 2020, 15, e0236057. [CrossRef]

34. Guideline for Programmatic Management of Drug Resistant TB in India; National TB Elimination Programme, Central TB Division, Ministry of Health \& Family Welfare Government of Indiae: New Delhi, India, 2021. Available online: https://tbcindia.gov.in/ showfile.php?lid=3590 (accessed on 1 August 2021).

35. Guideline for Programmatic Management of Tuberculosis Preventive Treatment in India; . National TB Elimination Programme, Central TB Division, Ministry of Health \& Family Welfare Government of India: New Delhi, India, 2021. Available online: https: / / tbcindia.gov.in/showfile.php?lid=3625 (accessed on 20 December 2021).

36. Osman, M.; du Preez, K.; Naidoo, P.; Bock, P.; Rabie, H.; Dlamini, S.S.; Hesseling, A.C. Key changes in the public health response to TB and HIV in South Africa. Int. J. Tuberc. Lung Dis. 2020, 24, 857-859. [CrossRef]

37. United Nations High-Level Meeting on TB: Country Targets for Childhood TB Diagnosis and Treatment. Available online: https:/ / www.stoptb.org/static_pages/ZAF_Dashboard.html (accessed on 22 December 2021).

38. Hoddinott, G.; Du Preez, K.; Osman, M.; Hirsch-Moverman, Y.; Viljoen, L.; Myburgh, H.; Wademan, D.; Meyerson, K.; Anthony, M.; Baloyi, D.; et al. A Review of Key Stakeholders' Perceptions of the Impediments and Facilitators of the Implementation of Tuberculosis Preventive Therapy (TPT) in South Africa; Technical Report Commissioned by the South African TB Think Tank; Stellenbosch University: Cape Town, South Africa, 2020.

39. Salazar-Austin, N.; Milovanovic, M.; West, N.S.; Tladi, M.; Barnes, G.L.; Variava, E.; Martinson, N.; Chaisson, R.E.; Kerrigan, D. Post-trial perceptions of a symptom-based TB screening intervention in South Africa: Implementation insights and future directions for TB preventive healthcare services. BMC Nurs. 2021, 20, 29. [CrossRef]

40. du Preez, K.; Osman, M.; Seddon, J.A.; Naidoo, P.; Schaaf, H.S.; Munch, Z.; Dunbar, R.; Mvusi, L.; Dlamini, S.S.; Hesseling, A.C. The impact of the evolving HIV response on the epidemiology of tuberculosis in South African children and adolescents. Clin. Infect. Dis. 2021, 73, e967-e975. [CrossRef] [PubMed]

41. du Preez, K.; Schaaf, H.S.; Dunbar, R.; Walters, E.; Swartz, A.; Solomons, R.; Hesseling, A.C. Complementary surveillance strategies are needed to better characterise the epidemiology, care pathways and treatment outcomes of tuberculosis in children. BMC Public Health 2018, 18, 397. [CrossRef] [PubMed]

42. Du Preez, K.; du Plessis, L.; O'Connell, N.; Hesseling, A.C. Burden, spectrum and outcomes of children with tuberculosis diagnosed at a district-level hospital in South Africa. Int. J. Tuberc. Lung Dis. 2018, 22, 1037-1043. [CrossRef]

43. Du Plessis, L.; Black, F.; Detjen, A.; Hesseling, A.C.; du Preez, K. Operational implementation and impact of The Union's online childhood TB training course in South Africa. Public Health Action 2017, 7, 175-177. [CrossRef] [PubMed]

44. Van Toorn, R.; Schaaf, H.S.; Laubscher, J.A.; van Elsland, S.L.; Donald, P.R.; Schoeman, J.F. Short intensified treatment in children with drug-susceptible tuberculous meningitis. Pediatr. Infect. Dis. J. 2014, 33, 248-252. [CrossRef]

45. Solomons, R.; Grantham, M.; Marais, B.J.; van Toorn, R. IMCI indicators of childhood TBM at primary health care level in the Western Cape Province of South Africa. Int. J. Tuberc. Lung Dis. 2016, 20, 1309-1313. [CrossRef]

46. Seddon, J.A.; Padayachee, T.; Du Plessis, A.M.; Goussard, P.; Schaaf, H.S.; Lombard, C.; Gie, R.P. Teaching chest X-ray reading for child tuberculosis suspects. Int. J. Tuberc. Lung Dis. 2014, 18, 763-769. [CrossRef]

47. Osman, M.; du Preez, K.; Seddon, J.A.; Claassens, M.M.; Dunbar, R.; Dlamini, S.S.; Welte, A.; Naidoo, P.; Hesseling, A.C. Mortality in South African children and adolescents routinely treated for tuberculosis. Pediatrics 2021, 147, e2020032490. [CrossRef]

48. Seddon, J.A.; Hesseling, A.C.; Godfrey-Faussett, P.; Schaaf, H.S. High treatment success in children treated for multidrug-resistant tuberculosis: An observational cohort study. Thorax 2014, 69, 458-464. [CrossRef]

49. du Preez, K.; Schaaf, H.S.; Dunbar, R.; Swartz, A.; Naidoo, P.; Hesseling, A.C. Closing the reporting gap for childhood tuberculosis in South Africa: Improving hospital referrals and linkages. Public Health Action 2020, 10, 38-46. [CrossRef]

50. Edginton, M.E.; Wong, M.L.; Hodkinson, H.J. Tuberculosis at Chris Hani Baragwanath Hospital: An intervention to improve patient referrals to district clinics. Int. J. Tuberc. Lung Dis. 2006, 10, 1018-1022. [PubMed] 
51. Marais, F.; Kallon, I.I.; Dudley, L.D. Continuity of care for TB patients at a South African hospital: A qualitative participatory study of the experiences of hospital staff. PLOS ONE 2019, 14, e0222421. [CrossRef] [PubMed]

52. Jong, E.; Sanne, I.M.; van Rie, A.; Menezes, C.N. A hospital-based tuberculosis focal point to improve tuberculosis care provision in a very high burden setting. Public Health Action 2013, 3, 51-55. [CrossRef] [PubMed]

53. Dudley, L.; Mukinda, F.; Dyers, R.; Marais, F.; Sissolak, D. Mind the gap! Risk factors for poor continuity of care of TB patients discharged from a hospital in the Western Cape, South Africa. PLoS ONE 2018, 13, e0190258.

54. Pillay, Y.; Pienaar, S.; Barron, P.; Zondi, T. Impact of COVID-19 on routine primary healthcare services in South Africa. S. Afr. Med. J. 2021, 111, 714-719. [CrossRef]

55. White, R.G.; Charalambous, S.; Cardenas, V.; Hippner, P.; Sumner, T.; Bozzani, F.; Mudzengi, D.; Houben, R.; Collier, D.; Kimerling, M.E.; et al. Evidence-informed policy making at country level: Lessons learned from the South African Tuberculosis Think Tank. Int. J. Tuberc. Lung Dis. 2018, 22, 606-613. [CrossRef]

56. Setiawaty, V.; Kosasih, H.; Mardian, Y.; Ajis, E.; Prasetyowati, E.B.; Siswanto, K.M. Sars-CoV-Reference Laboratory Ministry of Health Indonesia. The identification of first COVID-19 cluster in Indonesia. Am. J. Trop. Med. Hyg. 2020, 103, 2339-2342. [CrossRef]

57. Peta Sebaran COVID-19. Satuan Tugas Penanganan COVID-19. Available online: https://covid19.go.id/peta-sebaran-covid19 (accessed on 30 November 2021).

58. Sparrow, R.; Dartanto, T.; Hartwig, R. Indonesia under the new normal: Challenges and the way ahead. Bull. Indones. Econ. Stud. 2020, 56, 269-299. [CrossRef]

59. Mahendradhata, Y.; Andayani, N.L.P.E.; Hasri, E.T.; Arifi, M.D.; Siahaan, R.G.M.; Solikha, D.A.; Ali, P.B. The capacity of the Indonesian healthcare system to respond to COVID-19. Front. Public Health 2021, 9, 649819. [CrossRef]

60. Lestari, T.; Probandari, A.; Hurtig, A.K.; Utarini, A. High caseload of childhood tuberculosis in hospitals on Java Island, Indonesia: A cross sectional study. BMC Public Health 2011, 11, 784. [CrossRef]

61. Pakasi, T.T. Situasi dan Kebijakan Penanggulangan TBC pada Anak. In Proceedings of the the Orientasi Manajemen dan Tatalaksana TBC Anak dan TBC Laten di Indonesia Meeting, Jakarta, Indonesia, 21-22 July 2021.

62. Lestari, T.; Graham, S.; van den Boogard, C.; Triasih, R.; Poespoprodjo, J.R.; Ubra, R.R.; Kenangalem, E.; Mahendradhata, Y.; Anstey, N.M.; Bailie, R.S.; et al. Bridging the knowledge-practice gap in tuberculosis contact management in a high-burden setting: A mixed-methods protocol for a multicenter health system strengthening study. Implement. Sci. 2019, 14, 31. [CrossRef] [PubMed]

63. Aia, P.; Wangchuk, L.; Morishita, F.; Kisomb, J.; Yasi, R.; Kal, M.; Islam, T. Epidemiology of tuberculosis in Papua New Guinea: Analysis of case notification and treatment-outcome data, 2008-2016. West. Pac. Surveill. Response J. 2018, 9, 9-19. [CrossRef] [PubMed]

64. Lavu, E.; Johnson, K.; Banamu, J.; Pandey, S.; Carter, R.; Coulter, C.; Aia, P.; Majumdar, S.S.; Marais, B.; Graham, S.M.; et al. Drug-resistant tuberculosis diagnosis since Xpert MTB/RIF introduction in Papua New Guinea (2012-2017). Public Health Action 2019, 9 (Suppl. S1), S12-S18. [CrossRef] [PubMed]

65. Apis, V.; Landi, M.; Graham, S.M.; Islam, T.; Amini, J.; Sabumi, G.; Mandalakas, A.M.; Meae, T.; du Cros, P.; Shewade, H.D.; et al. Outcomes in children treated for tuberculosis with the new dispersible fixed-dose combinations in Port Moresby. Public Health Action 2019, 9 (Suppl. S1), S32-S37. [CrossRef]

66. Honjepari, A.; Madiowi, S.; Madjus, S.; Burkot, C.; Islam, S.; Chan, G.; Majumdar, S.S.; Graham, S.M. Implementation of screening and management of household contacts of tuberculosis cases in Daru, PNG. Public Health Action 2019, 9 (Suppl. S1), S25-S31. [CrossRef] [PubMed]

67. Tuberculosis Surveillance and Research Department of the National Center for Communicable Diseases. Tuberculosis Report 2015-2019; Tuberculosis Surveillance and Research Department of the National Center for Communicable Diseases: Ulaanbaatar, Mongolia, 2020.

68. Viney, K.; Islam, T.; Hoa, N.B.; Morishita, F.; Lönnroth, K. The financial burden of tuberculosis for patients in the Western-Pacific Region. Trop. Med. Infect. Dis. 2019, 4, 94. [CrossRef]

69. Tuberculosis Surveillance and Research Department of the National Center for Communicable Diseases. Tuberculosis Report 2020; Tuberculosis Surveillance and Research Department of the National Center for Communicable Diseases: Ulaanbaatar, Mongolia, 2021.

70. Ganmaa, D.; Uyanga, B.; Zhou, X.; Gantsetseg, G.; Delgerekh, B.; Enkhmaa, D.; Khulan, D.; Ariunzaya, S.; Sumiya, E.; Bolortuya, B.; et al. Vitamin-D supplements for prevention of tuberculosis infection and disease. N. Engl. J. Med. 2020, 383, 359-368. [CrossRef]

71. Rahevar, K.; Yuen, T.; Oh, K.H.; Kato, S.; Liu, Y.; Lijie, Z.; Gao, J.; Li, L.; Chen, Z.; Kim, C.T.; et al. Tuberculosis outbreaks in schools: Experiences from the Western Pacific Region. West. Pac. Surveill. Response J. 2021, 12, 1-5. [CrossRef]

72. Hoa, N.B.; Cobelens, F.G.; Sy, D.N.; Nhung, N.V.; Borgdorff, M.W.; Tiemersma, E.W. First national tuberculin survey in Viet Nam: Characteristics and association with tuberculosis prevalence. Int. J. Tuberc. Lung. Dis. 2013, 17, 738-744. [CrossRef]

73. Marks, G.B.; Nguyen, N.V.; Nguyen, P.T.B.; Nguyen, T.A.; Nguyen, H.B.; Tran, K.H.; Nguyen, S.V.; Luu, K.B.; Tran, D.T.T.; Vo, Q.T.N.; et al. Community-wide screening for tuberculosis in a high-prevalence setting. N. Engl. J. Med. 2019, 381, 1347-1357. [CrossRef] 
74. Vo, H.L.; Huynh, L.T.B.; Anh, H.N.S.; Do, D.A.; Doan, T.N.H.; Nguyen, T.H.T.; Van, H.N. Trends in socioeconomic inequalities in full vaccination coverage among Vietnamese children aged 12-23 months, 2000-2014: Evidence for mitigating disparities in vaccination. Vaccines 2019, 7, 188. [CrossRef] [PubMed]

75. Thanh, T.H.; Ngoc, S.D.; Viet, N.N.; Van, H.N.; Horby, P.; Cobelens, F.G.; Wertheim, H.F. A household survey on screening practices of household contacts of smear positive tuberculosis patients in Vietnam. BMC Public Health 2014, 14, 713. [CrossRef] [PubMed]

76. Schwoebel, V.; Koura, K.G.; Adjobimey, M.; Gnanou, S.; Wandji, A.G.; Gody, J.-C.; Delacourt, C.; Detjen, A.; Graham, S.M.; Masserey, E.; et al. Tuberculosis contact investigation and short-course preventive therapy among young children in four African countries. Int. J. Tuberc. Lung Dis. 2020, 24, 452-460. [CrossRef] [PubMed]

77. Koura, K.G.; Harries, A.D.; Fujiwara, P.I.; Dlodlo, R.A.; Sansan, E.K.; Kampoer, B.; Affolabi, D.; Combary, A.; Mbassa, V.; Gando, H.; et al. COVID-19 in Africa: Community and digital technologies for tuberculosis management. Int. J. Tuberc. Lung Dis. 2020, 24, 863-865. [CrossRef] [PubMed]

78. Kapata, N.; Chanda-Kapata, P.; Ngosa, W.; Metitiri, M.; Klinkenberg, E.; Kalisvaart, N.; Sunkutu, V.; Shibemba, A.; Chabala, C.; Chongwe, G.; et al. The prevalence of tuberculosis in Zambia: Results from the first National TB Prevalence Survey, $2013-2014$. PLoS ONE 2016, 11, e0146392. [CrossRef] [PubMed]

79. Chabala, C.; Chongwe, G.; Jumbe-Marsden, E.; Somwe, S.W. Missed opportunities for screening child contacts of smear-positive tuberculosis in Zambia, a high-prevalence setting. Int. J. Tuberc. Lung Dis. 2017, 21, 53-59. [CrossRef] [PubMed]

80. Kapata, N.; Chanda-Kapata, P.; O'Grady, J.; Bates, M.; Mwaba, P.; Janssen, S.; Marais, B.; Cobelens, F.; Grobusch, M.; Zumla, A. Trends in childhood tuberculosis in Zambia: A situation analysis. J. Trop. Pediatr. 2013, 59, 134-139. [CrossRef]

81. Chintu, C.; Mudenda, V.; Lucas, S.; Nunn, A.; Lishimpi, K.; Maswahu, D.; Kasolo, F.; Mwaba, P.; Bhat, G.; Terunuma, H.; et al. Lung diseases at necropsy in African children dying from respiratory illnesses: A descriptive necropsy study. Lancet 2002, 360, 985-990. [CrossRef]

82. Bates, M.; Shibemba, A.; Mudenda, V.; Chimoga, C.; Tembo, J.; Kabwe, M.; Chilufya, M.; Hoelscher, M.; Maeurer, M.; Sinyangwe, S.; et al. Burden of respiratory tract infections at post mortem in Zambian children. BMC Med. 2016, 14, 99. [CrossRef]

83. Kagujje, M.; Mubiana, M.L.; Mwamba, E.; Muyoyeta, M. Implementation of isoniazid preventive therapy in people living with HIV in Zambia: Challenges and lessons. BMC Public Health 2019, 19, 1329. [CrossRef]

84. Africa Centres for Disease Control and Prevention. Finding the Balance: Public Health and Social Measures in Zambia. Available online: https:/ / africacdc.org/download/ finding-the-balance-public-health-and-social-measures-in-zambia/ (accessed on 1 May 2021).

85. Mwamba, C.; Kerkhoff, A.D.; Kagujje, M.; Lungu, P.; Muyoyeta, M.; Sharma, A. Diagnosed with TB in the era of COVID-19: Patient perspectives in Zambia. Public Health Action 2020, 10, 141-146. [CrossRef] [PubMed]

86. Zawedde-Muyanja, S.; Nakanwagi, A.; Dongo, J.P.; Sekadde, M.P.; Nyinoburyo, R.; Sentongo, G.; Detjen, A.; Mugabe, F.; Nakaweesi, J.; Karamagi, Y.; et al. Decentralisation of child tuberculosis services increases case finding and uptake of preventive therapy in Uganda. Int. J. Tuberc. Lung Dis. 2018, 22, 1314-1321. [CrossRef]

87. Dongo, J.P.; Graham, S.M.; Nsonga, J.; Wabwire-Mangen, F.; Maleche-Obimbo, E.; Mupere, E.; Nyinoburyo, R.; Nakawesi, J.; Ssentongo, G.; Amuge, P.; et al. Implementation of an effective decentralized program for detection, treatment and prevention of tuberculosis in children. Trop. Med. Infect. Dis. 2021, 6, 131. [CrossRef] [PubMed]

88. Report of the First National Anti-Tuberculosis Drug Resistance Survey; Timor-Leste Ministry of Health: Dili, Timor-Leste, 2020.

89. Viney, K.; Amaral, S.; Marques, E.B.; Siroka, A.; Lopes, C.; Nery, S.V. Four of five tuberculosis patients experience catastrophic costs related to TB diagnosis and care in Timor-Leste. Int. J. Tuberc. Lung Dis. 2019, 23, 1191-1197. [CrossRef] [PubMed]

90. Country Profile: Timor-Leste. UNICEF. Geneva. 2021. Available online: https://data.unicef.org/country/tls / (accessed on 25 November 2021).

91. Hall, C.; Sukijthamapan, P.; dos Santos, R.; Nourse, C.; Murphy, D.; Gibbons, M.; Francis, J.R. Challenges to delivery of isoniazid preventive therapy in a cohort of children exposed to tuberculosis in Timor-Leste. Trop. Med. Int. Health 2015, 20, 730-736. [CrossRef] [PubMed]

92. Webster, P.C. Health in Colombia: A system in crisis. Can. Med. Assoc. J. 2012, 184, E289-E290. [CrossRef] [PubMed]

93. Arbelaez, M.P.; Gaviria, M.B.; Franco, A.; Restrepo, R.; Hincapié, D.; Blas, E. Tuberculosis control and managed competition in Colombia. Int. J. Health Plan. Manag. 2004, 19 (Suppl. S1), S25-S43. [CrossRef]

94. Ministry of Health and Social Protection. Survey on Difficulties and Barriers in the Control of Childhood and Adolescent TB. Departments and Cities: Arauca, Bogotá, Boyacá, Guaviare, Huila, La Guajira, Medellín, Putumayo, Quindí, Santander; National Tuberculosis Prevention and Control Program, Ministry of Health and Social Protection: Bogota, Colombia, 2021.

95. Fontalvo-Rivera, D.; Mazenett, E.; Cárcamo-Marrugo, L.; Llerena-Polo, C.; Gómez-Camargo, D. Tuberculosis in immigrants to Cartagena de Indias, Colombia. Int. J. Travel Med. Glob.Health 2020, 18, 100-106. [CrossRef]

96. Córdoba, C.; Luna, L.; Triana, D.M.; Perez, F.; López, L. Factors associated with delays in pulmonary tuberculosis diagnosis and treatment initiation in Cali, Colombia. Rev. Panam. Salud Publica 2019, 43, e14. [CrossRef]

97. Technical and Operational Guidelines of the National Tuberculosis Prevention and Control Program, National Tuberculosis Prevention and Control Program, Ministry of Health and Social Protection. Republic of Colombia, 2020. Available online: https:/ / www.minsalud.gov.co/Normatividad_Nuevo/Resoluci\%C3\%B3n\%20No.\%20227\%20de\%202020.pdf (accessed on 22 December 2021). 
98. Villegas, S.L.; Ferro, B.E.; Rojas, C.M.; Perez-Velez, C.M. Assessment of children exposed to adult pulmonary tuberculosis in Cali, Colombia. Paediatr. Int. Child. Health 2014, 34, 170-177. [CrossRef]

99. Zawedde-Muyanja, S.; Reuter, A.; Tovar, M.A.; Hussain, H.; Loando Mboyo, A.; Detjen, A.K.; Yuen, C.M. Provision of decentralized TB care services: A Detect-Treat-Prevent Strategy for children and adolescents affected by TB. Pathogens 2021, 10, 1568. [CrossRef] [PubMed]

100. Defeat Childhood TB: A Multi-country Assessment of National Policies and Preparedness for Childhood TB Programming-Call to Action; Elizabeth Glazer Pediatric AIDS Foundation: Washington, DC, USA; Unitaid: Geneva, Switzerland, 2021. 